Board of Governors of the Federal Reserve System

International Finance Discussion Papers

Number 596

November 1997

\title{
THE DEMAND FOR BROAD MONEY IN THE UNITED KINGDOM, 1878-1993
}

Neil R. Ericsson, David F. Hendry, and Kevin M. Prestwich

NOTE: International Finance Discussion Papers are preliminary materials circulated to stimulate discussion and critical comment. References to International Finance Discussion Papers (other than an acknowledgment that the writer has had access to unpublished material) should be cleared with the author or authors. Recent IFDPs are available on the Web at www.bog.frb.fed.us. 


\title{
THE DEMAND FOR BROAD MONEY IN THE UNITED KINGDOM, 1878-1993
}

\author{
Neil R. Ericsson, David F. Hendry, and Kevin M. Prestwich*
}

Abstract: Using annual data from Friedman and Schwartz (1982), Hendry and Ericsson (1991a) developed an empirical model of the demand for broad money in the United Kingdom over 1878-1975. We update that model over 1976-1993, accounting for changed data definitions and clarifying the concept of constancy. With appropriate measures of opportunity cost and credit deregulation, the model's parameters are empirically constant over the extended sample, which was economically turbulent. Policy implications follow for parameter nonconstancy and predictive failure, causation between money and prices, monetary targeting, deregulation and financial innovation, and the effect of policy on economic agents' behavior.

Keywords: constancy, financial innovation, Friedman and Schwartz, money demand.

*Forthcoming in the Scandinavian Journal of Economics, Vol. 100, No. 1, 1998. The first author is a staff economist in the Division of International Finance, Federal Reserve Board, Washington, D.C., U.S.A. The second author is Leverhulme Personal Research Professor of Economics at Nuffield College, Oxford, England. The third author was a research assistant in the Division of International Finance at the Federal Reserve Board when this paper was initially drafted. The authors may be reached on the Internet at ericsson@frb.gov, david.hendry@nuffield.oxford.ac.uk, and kevin_prestwich@mail.amsinc.com respectively. The views in this paper are solely the responsibility of the authors and should not be interpreted as reflecting the views of the Board of Governors of the Federal Reserve System or of any other person associated with the Federal Reserve System. The first author gratefully acknowledges the generous hospitality of Norges Bank, where he revised some of the material herein. The second author gratefully acknowledges financial support from the U.K. Economic and Social Research Council under grant R000234954. We wish to thank Chris Allsopp, Torben Andersen, Peter Hammond, Svend Hylleberg, Neva Kerbeshian, Jaime Marquez, Karl Moene, John Muellbauer, Timo Teräsvirta, a referee, the participants at the Lysebu conference, and workshop participants at the Oxford Institute of Economics and Statistics and the University of California at San Diego for helpful discussions and comments; and Clifford Attfield, David Demery, and Nigel Duck for compiling the data in Attfield, Demery, and Duck (1995). All numerical results were obtained using PcGive Professional Versions 8.10 and 9.00: see Doornik and Hendry (1994), Doornik and Hendry (1996), and Hendry and Doornik (1996). This paper is being simultaneously circulated as Working Paper (Arbeidsnotat) No. 1997/12 by the Research Department of Norges Bank, and as International Finance Discussion Paper No. 596 by the Board of Governors of the Federal Reserve System. The latter can be obtained at www.bog.frb.fed.us/pubs/ifdp/1997/596/default.htm on the WorldWide Web. 


\section{Introduction}

We are delighted to contribute to a volume celebrating the centenary of the Scandinavian Journal of Economics, and we offer our birthday greetings to a journal that has played a distinguished role in the development of our science over the last century. As befits such an occasion, this paper reconsiders a perennial controversy with important policy implications — the demand for money — using a long historical data record for the United Kingdom.

This re-assessment emphasizes the intertwining of empirical modeling, econometric methodology, and conceptual issues when evaluating econometric models over additional observations. Hendry and Ericsson (1991a) developed a model of U.K. money demand on data spanning 1878-1975. In the current paper, we extend that model to include nearly two decades of new data for 1976-1993, and, in so doing, clarify the concept of parameter constancy. Lengthening the sample expands the number of alternative measures of both credit derestrictions and the opportunity cost of holding money. Thus, we test for parameter constancy in models using different measures of those concepts. Mechanistic updates of these measures result in models with predictive failure. However, for coherent updates, the model's short-run and long-run properties remain virtually unchanged over the unusually long forecast period of 18 years, despite substantial financial innovation in the economy and major changes in monetary control rules.

Sections II, III, and V focus on the empirical aspects, and Section IV on the methodological and conceptual developments. The empirical, methodological, and conceptual contributions all have implications for inferences about economic policy, and all help in understanding those implications. Section V.3 discusses several such implications, including the role of parameter nonconstancy and predictive failure, the direction of causation between money and prices, monetary targeting, deregulation and financial innovation, the Lucas critique, the role of expectations in economic agents' decisions, and the effect of policy on economic agents' behavior. The paper's results also have ramifications for the modeling and analysis of other sectors of the U.K. economy and of sectors of other countries' economies.

In somewhat greater detail, the structure of the paper is as follows. Section II briefly reviews the economic theory of money demand and defines and describes the data series. Section III records the estimated model in Hendry and Ericsson (1991a) and notes its nonconstancy if the model is extended mechanistically over the new data. Section IV considers how to evaluate and update empirical models over samples involving major changes to the economy. Specifically, for the forecast period 1976-1993, economic extensions of the empirical model are required for the changing 
measurement of money, for the associated changes in the opportunity cost of holding money, and for financial innovation and deregulation. Data measurement, the opportunity cost, and financial innovation and deregulation each have implications for parameter constancy. Section V extends the economics of the model in Hendry and Ericsson (1991a) to incorporate these issues, and it tests for and shows the constancy of the model's parameters. This section also considers identification and policy implications. Section VI concludes. Ericsson, Hendry, and Prestwich (1997) document the data in detail and compare the performance of the annual model with other models, including with models based on Friedman and Schwartz's phase-average data.

\section{Economic Theory and Data Description}

This section provides the backdrop for the subsequent sections. Section II.1 sketches the standard theory underlying empirical models of money demand. Section II.2 describes the data modeled and characterizes the data's basic properties.

\section{II.1 Economic Theories of Money Demand}

The theoretical and empirical study of the demand for money in the United Kingdom has an impressive history, matching the extensive time series now available on money and its main determinants. See Jevons (1884) [reprinted in part as Hendry and Morgan (1995, Chapter 6)], Marshall (1926), Keynes (1930), and Hawtrey (1938) inter alia for earlier contributions. More recently, the literature on money demand has seen an explosion in the modeling of numerous monetary aggregates, both for the United Kingdom and for other countries. Goldfeld and Sichel (1990) extensively review that more recent theoretical and empirical work.

As discussed in the papers cited above, and elsewhere, money may be demanded in a modern economy for at least two reasons: as an inventory to smooth differences between income and expenditure streams, and as one among several assets in a portfolio. Both demands lead to a long-run specification in which nominal money demanded $\left(M^{d}\right)$ depends on the price level $(P)$, a scale variable $(I)$, inflation $(\dot{p})$, and a vector $(\mathbf{R})$ of rates of returns on various assets:

$$
M^{d}=g(P, I, \dot{p}, \mathbf{R}) .
$$

The function $g(\cdot)$ is assumed to be unit homogeneous in $P$, increasing in $I$, decreasing in both inflation and those elements of $\mathbf{R}$ associated with assets excluded from money $(M)$, and increasing in those elements of $\mathbf{R}$ for assets included in $M$. The op-

portunity cost is determined through $\mathbf{R}$ and is the focus of Section IV.2. See Cagan (1956) on the inclusion of $\dot{p}$ in $g(\cdot)$. 
Commonly, (1) is specified in log-linear form, albeit with interest rates entering either in logs or in levels:

$$
m^{d}-p=\mu_{0}+\mu_{1} i+\mu_{2} \dot{p}+\mu_{3} R^{\text {own }}+\mu_{4} R^{\text {out }} .
$$

Capital letters denote both the generic name and the level, logs are in lowercase, and (somewhat symbolically) $R^{\text {own }}$ and $R^{\text {out }}$ denote the own and outside rates of interest. The coefficients $\mu_{0}, \ldots, \mu_{4}$ are an intercept, the income elasticity, and the semi-elasticities on inflation, the own interest rate, and the outside interest rate. Anticipated signs of the coefficients are $\mu_{1}>0, \mu_{2}<0, \mu_{3}>0$, and $\mu_{4}<0$.

\section{II.2 Data Description}

This subsection defines the data and presents some descriptive statistics. Both graphs and simple time-series regressions help characterize the data's properties, which should be considered in empirical modeling.

The basic data series are annual values of the broad money stock $(M)$, real net national income $(I)$, the corresponding deflator $(P)$, short-term and long-term nominal interest rates $(R S$ and $R \ell)$, and high-powered money $(H)$, all for the United Kingdom. Data from 1871 to 1975 are from Friedman and Schwartz (1982). Attfield, Demery, and Duck (1995) extended those series over 1976-1993, constructing them from a variety of sources and splicing together several alternative definitions of money. Section IV.1 below discusses these measures of money as such. The variables $M$ and $H$ are in $£$ million; $I$ is in $£$ million for $1929 ; P=1.00$ in 1929 ; and $R S$ and $R \ell$ are fractions.

Some constructed variables are also of interest. First, under the quantity theory of money, the income elasticity is unity $\left[\mu_{1}=1\right.$ in $\left.(2)\right]$, so a key derived variable is velocity $V$, constructed as $(I \cdot P) / M$. Second, there are dummy variables. Retaining the notation in Hendry and Ericsson (1991a), the variables $D_{1}$ and $D_{3}$ are zero-one dummies for World Wars I and II, and $D_{4}$ is a zero-one dummy for 1971-1975. The latter aims to capture the deregulation of the banking sector with the introduction of Competition and Credit Control in 1971. A similar period of deregulation occurs in 1986-1989; see Section IV.3 below. As a proxy for both episodes of deregulation, the dummy $D_{c}$ is unity for 1971-1975 and 1986-1989, and zero otherwise. See Friedman and Schwartz (1982), Topping and Bishop (1989), Hendry and Ericsson (1991a), Attfield, Demery, and Duck (1995), and Ericsson, Hendry, and Prestwich (1997) for details on this data and on the additional data discussed below.

Finally, before examining the data, we introduce a few more conventions. Uppercase delta $\Delta$ is the difference operator. "Levels" often means the logarithm of

\footnotetext{
${ }^{1}$ The difference operator $\Delta$ is defined as $(1-L)$, where the lag operator $L$ shifts a variable one period into the past. Hence, for $x_{t}$ (a variable $x$ at time $t$ ), $L x_{t}=x_{t-1}$ and so $\Delta x_{t}=x_{t}-x_{t-1}$. More generally, $\Delta_{j}^{i} x_{t}=\left(1-L^{j}\right)^{i} x_{t}$ for positive integers $i$ and $j$. If $i$ or $j$ is not explicit, it is taken to be unity.
} 

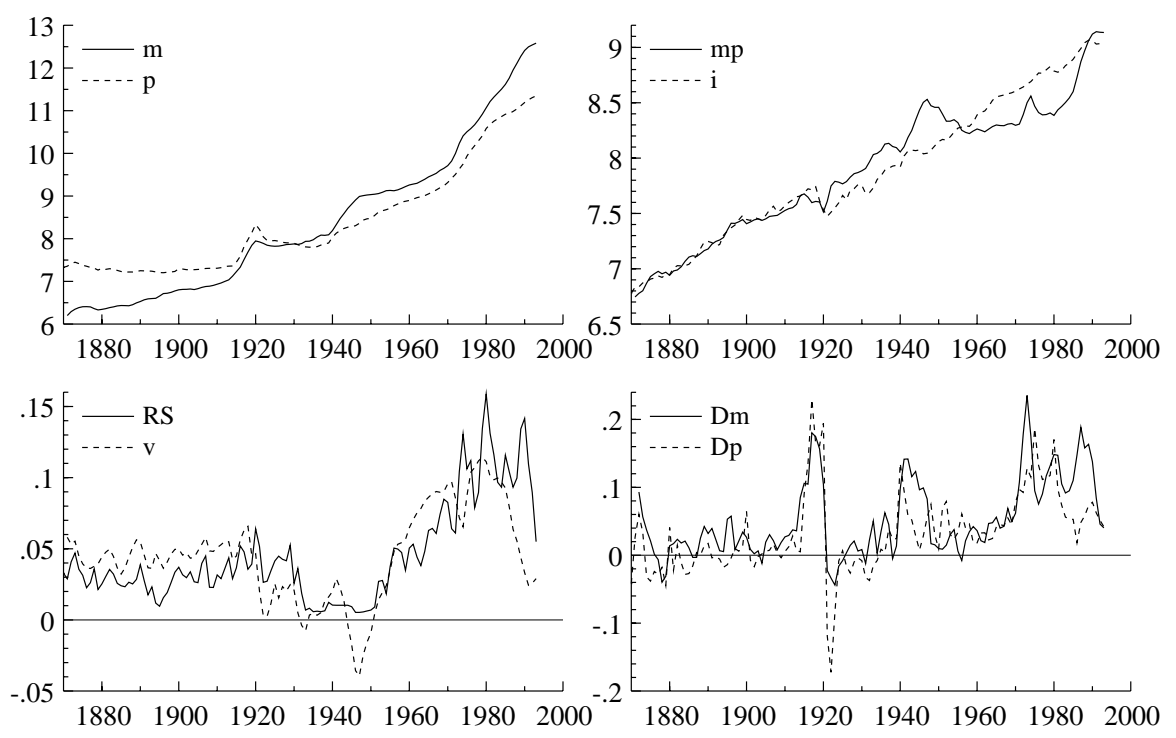

Figure 1: Nominal money and prices $(m, p)$, real money and real income $(m-p, i)$, interest rates and velocity $(R S, \nu)$, and money growth and inflation $(\Delta m, \Delta p)$.

the levels, and the context clarifies this. Figures typically appear as $2 \times 2$ panels of graphs, with each graph labeled by a suffix $a, b, c$, or $d$, as follows: $\left[\begin{array}{ll}a & b \\ c & d\end{array}\right]$. Single and double asterisks $\left(*\right.$ and $\left.*^{*}\right)$ adjacent to values of statistics denote significance at the $5 \%$ and $1 \%$ levels.

Figure 1 shows the full-sample time series of $(m, p),(m-p, i),(R S, \nu)$, and $(\Delta m, \Delta p)$ as a $2 \times 2$ panel, with the variables adjusted for their means in the first two graphs and for their means and ranges in the third graph. Figure 1a emphasizes the huge changes in money and prices over the century. Noting that the graph is in logs (for ease of display), the actual level of money moves from £492.4 million in 1871 to $£ 291,173$ million in 1993, an increase of almost 600-fold. Over the same period, prices rise about 55-fold, from 0.579 to 31.38 . Thus, a pound sterling in 1993 is equivalent in purchasing power to just over $4 \mathrm{~d}$ (approximately 2 new pence) at the beginning of the sample. From Figure 1b, real money increases 10.9-fold over the sample, closely matching the 9.2-fold increase in real national income. To characterize adequately such massive growth and change in money is a serious challenge, particularly in a parsimonious constant model.

As Figure 1b also shows, real money grows most rapidly over the last two decades, notwithstanding the two world wars elsewhere in the sample and despite the U.K. government's attempt at monetary control over much of the 1980s. Correspondingly, velocity falls sharply to levels prevalent in the last century; see Figure 1c. Even 
relative to the previous century, large changes have occurred over the last two decades.

Figure 1d plots the inflation rate and the growth rate of nominal money. These series move relatively closely overall. There are four notable departures: 1920-1922, when prices fall by $25 \%$ but nominal money by only $5 \%$; World War II and the early 1970s, when money growth greatly exceeds the rate of inflation; and 1985-1990, when money growth is about $17 \%$ with inflation of $6 \%$.

Univariate autoregressive models can help characterize the order of integration of time series for use in subsequent cointegration analysis. Specifically, the augmented Dickey-Fuller $(\mathrm{ADF})$ statistic $t_{A D F}$ can be used to test whether a series is integrated of order $d$ [or $\mathrm{I}(d)]$, where an $\mathrm{I}(d)$ series requires differencing $d$ times to remove all its unit roots; see Dickey and Fuller (1981). Table 1 records the ADF statistics over the sample 1875-1993 for the key variables. Each ADF statistic is reported for the shortest lag length obtainable (commencing from 2 lags) without dropping a lagged difference significant at the $5 \%$ level.

The hypothesis of a unit root cannot be rejected for any variable in levels, whereas it is strongly rejected for all variables in differences, consistent with the visual evidence that the differences repeatedly return to their means over the sample. Despite their smooth and trending appearance, $m$ and $p$ appear to be $\mathrm{I}(1)$ rather than $\mathrm{I}(2)$. The smoothness in $m$ and $p$ may be associated with the main regime shifts over the sample, such as wars and financial innovations. If so, a non-negligible part of their observed variation may be due to non-stationarities arising from structural change. Thus, given their univariate nature and the absence of tests for congruency, these ADF (and related) statistics should not be regarded as definitive.

The I(1)-ness of $m$ and $p$ contrasts with evidence in Johansen (1992), who finds money and prices in the United Kingdom to be $\mathrm{I}(2)$. These discrepant results have several potential explanations. First, the data differ and so need not have the same order of integration. Johansen's data are M1 and the implicit price deflator for total final expenditure, whereas our data are M2 (recently, M3 and M4) and the implicit price deflator for net national income. Second, the testing procedures differ, with potentially different size and power properties. Johansen tests for integration by a system-based procedure, whereas the ADF statistics in Table 1 are univariate. Third, and relatedly, both measures of money and prices display regime shifts, which are liable to affect the properties of the test procedures; see Figure 1d and Johansen (1992, Figure 2). Fourth, the order of integration need not be an inherent property of data. For instance, the order might alter over time, due to changes in government policy or economic innovation. Subsample values of first-order augmented Dickey-Fuller statistics provide evidence on both the third and fourth issues. For the change in a given variable, the corresponding recursive values of $t_{A D F}$ should decline monotonically over time if the original variable is $\mathrm{I}(1)$, or remain relatively flat if the original variable is $\mathrm{I}(2)$. For each measure of money and of prices, the recursive values of $t_{A D F}$ do neither, but rather increase sharply over some periods and decrease sharply 
Table 1. ADF Statistics and Related Calculations

\begin{tabular}{lcrccrcc}
\hline \hline Variable & \multicolumn{1}{c}{$t_{A D F}$} & $\hat{\rho}$ & $\hat{\sigma}$ & Lag & \multicolumn{1}{c}{$t_{\text {lag }}$} & $t_{\text {lag }}$-prob (\%) & $F$-prob (\%) \\
\hline$m$ & & & & & & & \\
$p$ & -0.44 & 0.997 & 0.0263 & 2 & -4.58 & 0.0 & - \\
$i$ & -1.29 & 0.990 & 0.0396 & 1 & 9.47 & 0.0 & 16.7 \\
$m-p$ & -2.67 & 0.913 & 0.0313 & 1 & 3.54 & 0.1 & 88.8 \\
$\nu$ & -2.78 & 0.934 & 0.0356 & 1 & 7.23 & 0.0 & 6.2 \\
$R S$ & -2.35 & 0.949 & 0.0428 & 1 & 6.05 & 0.0 & 52.7 \\
$R \ell$ & -2.28 & 0.897 & 0.0124 & 2 & -3.59 & 0.0 & - \\
$R N^{a}$ & -2.35 & 0.936 & 0.0059 & 1 & 3.60 & 0.0 & 5.9 \\
$\hat{u}$ & -1.66 & 0.925 & 0.0099 & 2 & -4.39 & 0.0 & - \\
$\tilde{u}$ & $-5.17^{* *}$ & 0.695 & 0.0901 & 1 & 3.84 & 0.0 & 8.4 \\
& -3.30 & 0.790 & 0.0696 & 2 & -3.16 & 0.2 & - \\
$\Delta m$ & & & & & & & \\
$\Delta p$ & $-5.18^{* *}$ & 0.725 & 0.0262 & 1 & 5.01 & 0.0 & 41.9 \\
$\Delta i$ & $-4.87^{* *}$ & 0.658 & 0.0397 & 0 & - & - & 29.0 \\
$\Delta(m-p)$ & $-7.24^{* *}$ & 0.042 & 0.0316 & 2 & 2.36 & 2.0 & - \\
$\Delta \nu$ & $-6.72^{* *}$ & 0.408 & 0.0358 & 1 & 2.62 & 1.0 & 15.7 \\
$\Delta R S$ & $-6.58^{* *}$ & 0.463 & 0.0436 & 0 & - & - & 22.5 \\
$\Delta R \ell$ & $-10.22^{* *}$ & -0.244 & 0.0126 & 1 & 4.26 & 0.0 & 5.3 \\
$\Delta R N^{a}$ & $-1.61^{* *}$ & 0.139 & 0.0059 & 1 & 2.29 & 2.4 & 6.3 \\
$\Delta \hat{u}$ & $-8.34^{* *}$ & -0.269 & 0.0100 & 1 & 5.08 & 0.0 & 28.1 \\
$\Delta \tilde{u}$ & $-9.24^{* *}$ & -0.369 & 0.0928 & 2 & 2.33 & 2.2 & - \\
& & -0.420 & 0.0714 & 2 & 2.16 & 3.3 & - \\
\hline \hline
\end{tabular}

Notes:

1. Second-order ADF regressions were initially estimated and, in an iterative sequence, the longest lag was repeatedly dropped until its $t$-ratio was at least two in absolute value. For each variable examined, the columns report the ADF statistic on this simplified regression $\left(t_{A D F}\right)$, the estimated coefficient on the lagged level that is being tested for a unit value $(\hat{\rho})$, the estimated equation standard error $(\hat{\sigma})$, the lag length of the ADF regression (lag), the $t$-statistic on the longest lag of the final regression $\left(t_{\text {lag }}\right)$, its tail probability $\left(t_{\text {lag }}\right.$-prob), and the tail probability of the $F$ statistic for the lags dropped ( $F$-prob). Sections III and V define $\hat{u}$ and $\tilde{u}$.

2. All of the ADF regressions include both an intercept and a linear trend. MacKinnon's (1991) approximate finite-sample critical values for the corresponding ADF statistic are $-3.45(5 \%)$ and $-4.04(1 \%)$, except for $\hat{u}, \tilde{u}, \Delta \hat{u}$, and $\Delta \tilde{u}$, for which the critical values are $-3.86(5 \%)$ and $-4.46(1 \%)$. The sample is $1875-1993$ $(T=119)$ in all cases. Rejection of the null hypothesis of a unit root is denoted by * and ${ }^{* *}$ for the $5 \%$ and $1 \%$ levels. 
over others, where the precise datings of the movements depend on the series and dataset. Fifth, the samples differ. Johansen's data are quarterly over 1964-1989, our data are annual over 1875-1993, and the characteristics of the economy vary over the respective sample periods.

\section{Previous Estimates and a Mechanistic Extension}

Section III.1 presents the initial annual model in Hendry and Ericsson (1991a) and their alternative model on a slightly different sample. Both models use the annual data as compiled by Friedman and Schwartz (1982), which end in 1975. Section III.2 evaluates a simple mechanistic extension of Hendry and Ericsson's model over the sample 1976-1993 and finds strong evidence of parameter nonconstancy. However, the way in which a model is extended over a new sample bears directly on its statistical performance on that sample, leading to economic extensions of empirical models (Section IV) and a re-evaluation of the model in Hendry and Ericsson (1991a) on the new data (Section V).

\section{III.1 The Annual Models in Hendry and Ericsson (1991a)}

Economic theory offers little guidance in modeling the behavior of money out of equilibrium, beyond saying that adjustments to "desired" levels of money holdings are likely to take time, due to adjustment costs. In that light, Hendry and Ericsson (1991a) developed a dynamic equilibrium correction model (EqCM) of broad money $M$, allowing the economic theory above to define the long-run equilibrium while determining short-run dynamics from the data. ${ }^{2}$ That EqCM is:

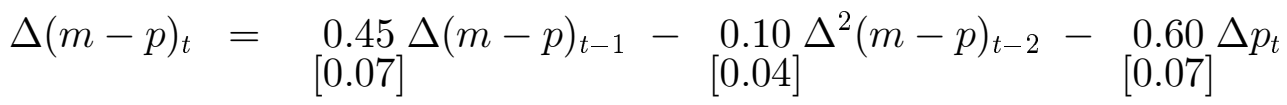

$$
\begin{aligned}
& +\underset{[0.07]}{0.39 \Delta p_{t-1}}-\underset{[0.006]}{0.021 \Delta r s_{t}}-\underset{[0.023]}{0.062 \Delta_{2} r \ell_{t}} \\
& -\underset{[0.67]}{2.54}\left(\hat{u}_{t-1}-0.2\right) \hat{u}_{t-1}^{2}+\underset{[0.002]}{0.005}+\underset{[0.7]}{3.7}\left(D_{1}+D_{3}\right)_{t} \\
& T=93[1878-1970] \quad R^{2}=0.87 \quad \hat{\sigma}=1.424 \% \quad d w=1.82 \\
& \text { AR }: F(2,82)=1.39 \quad \text { ARCH }: F(1,82)=1.51 \quad \text { Normality }: \chi^{2}(2)=1.9 \\
& \text { RESET }: F(1,83)=0.41 \text { Hetero }: F(15,68)=0.87 \quad \text { Form }: F(43,40)=0.81 \\
& J t=1.18 \text { Var }=0.09 \text {. }
\end{aligned}
$$

\footnotetext{
${ }^{2}$ Although Hendry and Ericsson (1991a) called the model in (3) below an error correction model, technically speaking it is an equilibrium correction model. See Hendry (1995, p. 213) for a discussion of the distinction between the two.
} 
Here and below, $t$ is the annual time subscript; $T$ is the number of annual observations; $R^{2}$ is the squared multiple correlation coefficient; $\hat{\sigma}$ is the standard deviation of the residuals, expressed as a percentage of real money and adjusted for degrees of freedom; and the coefficient on the war dummies $\left(D_{1}+D_{3}\right)$ has been scaled up 100-fold so that it is interpretable as a percentage. OLS standard errors are in parentheses $(\cdot)$, whereas heteroscedasticity-consistent standard errors are in square brackets [.]; see White (1980), Nicholls and Pagan (1983), Messer and White (1984), and MacKinnon and White (1985) on the latter. Equation (3) also includes diagnostic statistics for testing against various alternative hypotheses: residual autocorrelation ( $d w$ and $A R)$, autoregressive conditional heteroscedasticity $(A R C H)$, skewness and excess kurtosis (Normality), RESET (RESET), heteroscedasticity (Hetero), heteroscedasticity quadratic in the regressors (alternatively, functional form mis-specification) (Form), and joint parameter nonconstancy and variance nonconstancy ( $J t$ and $V a r){ }^{3,4}$ The asymptotic null distribution is designated by $\chi^{2}(\cdot)$ or $F(\cdot, \cdot)$, the degrees of freedom fill the parentheses, and (for $A R$ and $A R C H$ ) the lag order is the first degree of freedom.

The derived variable $\hat{u}$ in (3) is the equilibrium correction residual from the static Engle-Granger regression over 1873-1970:

$$
\begin{gathered}
(m-p-i)_{t}=-0.310-7.00 R S_{t} \\
T=98[1873-1970] \quad R^{2}=0.56 \quad \hat{\sigma}=10.86 \% \quad d w=0.33 \quad t_{A D F}=-2.77 ;
\end{gathered}
$$

see Engle and Granger (1987). Based on Escribano (1985), $\hat{u}$ enters (3) nonlinearly.

Equation (3) appears reasonably well specified within sample, given the diagnostic statistics above and additional results in Hendry and Ericsson (1991a). In particular, Hendry and Ericsson (1991a) provide graphical evidence that (3) is empirically constant, using recursive least squares.

However, (3) as specified is nonconstant over the period 1971-1975, following the introduction of Competition and Credit Control regulations (CCC). Hendry and Ericsson (1991a) expand (3) to account for CCC by including the dummy $D_{4}$, both by itself and interactively with $\Delta$ rs. Estimated over 1878-1975, the resulting model

\footnotetext{
${ }^{3}$ For derivations of the test statistics, see Godfrey (1978), Engle (1982), Doornik and Hansen (1994), Ramsey (1969), White (1980) (for both Hetero and Form), and Hansen (1992) (for both Jt and Var). For additional discussion and for their implementation, see Hendry and Doornik (1996).

${ }^{4}$ Due to increased numerical accuracy in recent versions of PcGive, some coefficients and test statistics in (3), (4), and (5) differ slightly from those reported in the equivalent equations in Hendry and Ericsson (1991a). See Doornik and Hendry (1992, Appendix C) and Hendry and Doornik (1996, Appendix A2) for details on the specific improvements in accuracy, noting that the results in Hendry and Ericsson (1991a) were produced with PcGive version 6.0/6.01. Also, the heteroscedasticityconsistent standard errors in Hendry and Ericsson (1991a) are those from White (1980), whereas the ones reported herein are the jackknife version from MacKinnon and White (1985).
} 

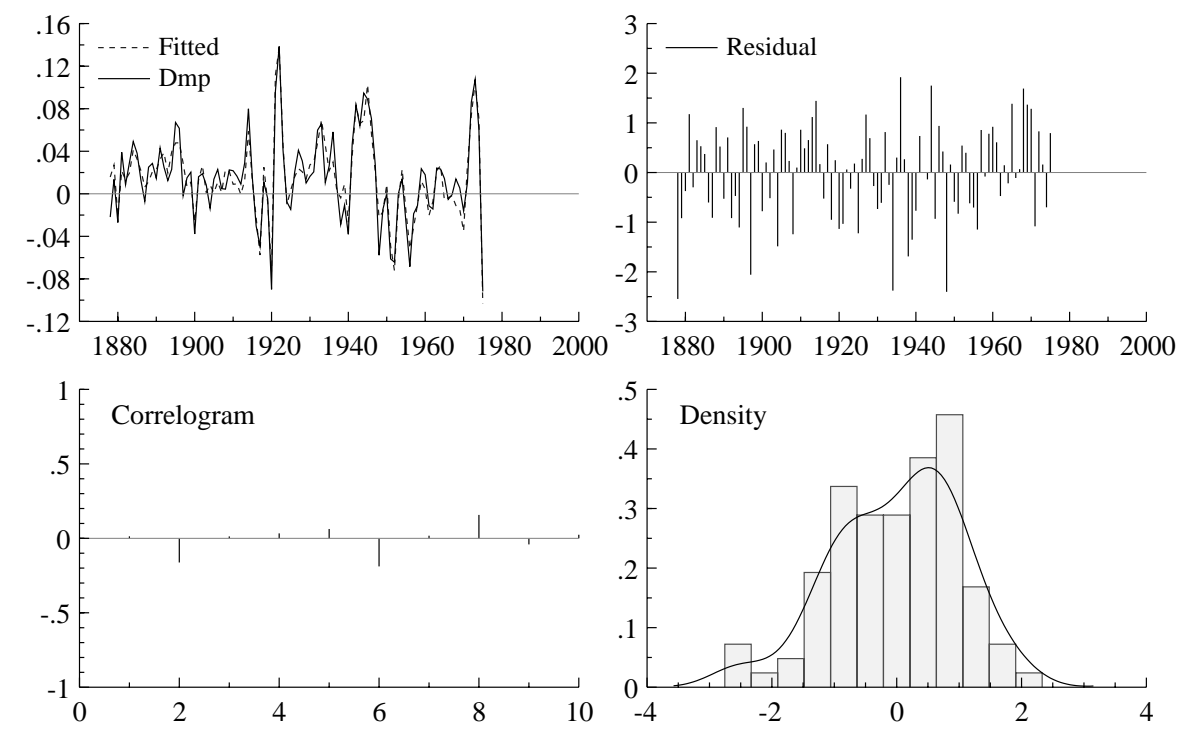

Figure 2: Fitted and actual values of $\Delta(m-p)_{t}$ from (5), and the corresponding scaled residuals, residual correlogram, and residual histogram and estimated density.

is close to (3) for comparable coefficients:

$$
\begin{aligned}
& \Delta(m-p)_{t}=\underset{[0.06]}{0.47} \Delta(m-p)_{t-1}-\underset{[0.04]}{0.11} \Delta^{2}(m-p)_{t-2}-\underset{[0.06]}{0.59 \Delta p_{t}} \\
& +\underset{[0.07]}{0.41} \Delta p_{t-1}-\underset{[0.008]}{0.017} \Delta r s_{t}-\underset{[0.026]}{0.078} \Delta_{2} r \ell_{t} \\
& -\underset{[1.46]}{1.15}\left(\hat{u}_{t-1}-0.2\right) \hat{u}_{t-1}^{2}+\underset{[0.003]}{0.007}+\underset{[0.8]}{3.4}\left(D_{1}+D_{3}\right)_{t} \\
& +\underset{[1.8]}{7.1} D_{4 t}+\underset{[0.046]}{0.090 D_{4 t} \cdot \Delta r s_{t}} \\
& T=98[1878-1975] \quad R^{2}=0.88 \quad \hat{\sigma}=1.478 \% \quad d w=1.89 \\
& \text { AR }: F(2,85)=1.50 \quad \text { ARCH }: F(1,85)=1.43 \quad \text { Normality }: \chi^{2}(2)=4.2 \\
& \text { RESET }: F(1,86)=0.03 \quad \text { Hetero }: F(18,68)=0.43 \quad \text { Form }: F(48,38)=0.97 \\
& J t=1.22 \quad \text { Var }=0.05 \text {. }
\end{aligned}
$$

As with $\left(D_{1}+D_{3}\right)$, the coefficient on $D_{4}$ (and on $D_{c}$, below) has been scaled up 100fold - when it enters the equation as $D_{4}$ (or as $D_{c}$ ) alone. The coefficient on $D_{4 t} \cdot \Delta r s_{t}$ is not rescaled, so as to maintain units comparable to those of the coefficient on $\Delta r s_{t}$. Figure 2 shows the fitted and actual values, scaled residuals (scaled to be in units 
of $\hat{\sigma}$ ), residual correlogram, and residual histogram and estimated density for (5). The model appears congruent within this sample against the available information.

\section{III.2 Predictive Failure of a Mechanistic Extension of the Model}

In evaluating a model over a new sample, a common approach updates the model mechanistically, simply "plugging in" the new data into the existing equation. For (5) and the data described in Section II.2, the results are as follows over the 18 years of new data:

$$
\begin{aligned}
& \Delta(m-p)_{t}=\underset{[0.07]}{0.54} \Delta(m-p)_{t-1}-\underset{[0.05]}{0.11} \Delta^{2}(m-p)_{t-2}-\underset{[0.09]}{0.63 \Delta} \Delta p_{t} \\
& +\underset{[0.08]}{0.47 \Delta p_{t-1}}-\underset{[0.007]}{0.008} \Delta r s_{t}-\quad 0.089 \Delta_{2} r \ell_{t} \\
& -\underset{[0.072]}{0.056}\left(\hat{u}_{t-1}-0.2\right) \hat{u}_{t-1}^{2}+\underset{[0.002]}{0.009}+\underset{[0.7]}{3.1}\left(D_{1}+D_{3}\right)_{t} \\
& +\underset{[1.4]}{5.0 D_{c t}}+\underset{[0.059]}{0.126 D_{4 t}} \cdot \Delta r s_{t} \\
& T=116[1878-1993] \quad R^{2}=0.82 \quad \hat{\sigma}=1.931 \% \quad d w=1.48 \\
& A R: F(2,103)=4.32^{*} \quad A R C H: F(1,103)=0.01 \quad \text { Normality }: \chi^{2}(2)=4.2 \\
& \text { RESET }: F(1,104)=0.92 \text { Hetero }: F(18,86)=3.74^{* *} \text { Form }: F(52,52)=2.83^{* *} \\
& \text { Chow }: F(18,87)=5.13^{* *} \quad J t=2.58 \quad \text { Var }=0.86^{* *} \text {. }
\end{aligned}
$$

Despite the benefit of using $D_{c}$ (the extended dummy for credit loosening), (6) appears nonconstant. The Chow (1960) predictive-failure statistic (Chow) strongly rejects constancy; Hansen's statistic Var likewise rejects constancy; and Jt nearly rejects at the $90 \%$ critical value, even though it has 12 degrees of freedom. Several residual diagnostic tests also reject, and the equilibrium correction term has become insignificant.

Predictive failure is extensive and not isolated to one or two observations. Figure 3 demonstrates this failure through the fitted, actual, and forecast values for $\Delta(m-p)_{t}$, their cross-plots, the equation's residuals, and the equation's forecasts (with \pm 2 standard error bars) compared with actual outcomes. Both numerically and statistically, the model's forecast performance is dramatically worse than its in-sample behavior.

\section{Economic Extensions of Empirical Models}

Mechanical extensions of an empirical model, such as (6), can mislead because of their simplistic approach to updating. Rather, changing environments may require 

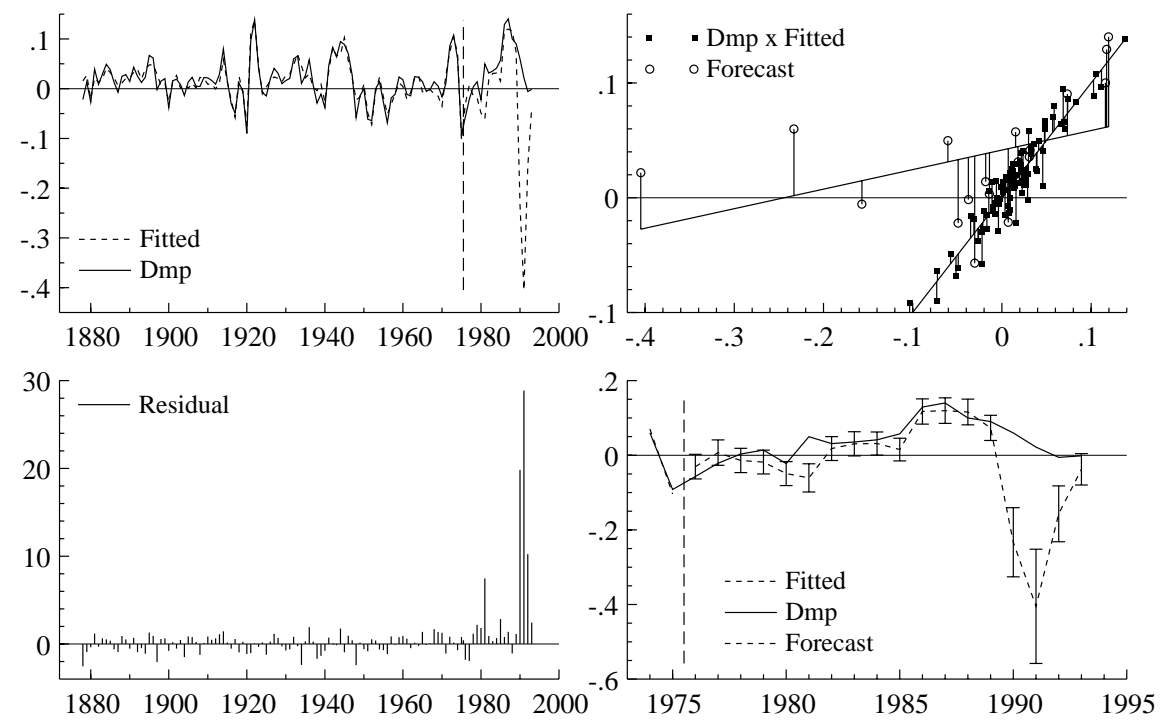

Figure 3: Fitted, actual, and forecast values of $\Delta(m-p)_{t}$ from (5), and their crossplots, corresponding scaled residuals, and forecasts with \pm 2 standard error bands.

economic adaptation of a model. To that end, this section considers four issues. First, Section IV.1 examines how the adopted measure of money changes when extending the data series. Second, Section IV.2 derives the consequent effects on the opportunity cost of holding the new measure of money. Third, Section IV.3 discusses the effect of financial innovation and financial deregulation on both the original measure of money and the new measure. Fourth, Section IV.4 analyzes statistical implications for a model's constancy over an extended sample with financial innovation and changed data definitions and opportunity costs. Section IV.5 summarizes, and considers alternative approaches.

\section{IV.1 Measures of Money}

This subsection reviews some difficulties in measuring money, and then focuses on the specific statistical measures used herein. Difficulties include vagueness in the concept of money itself, the effects of financial innovation on measurement of a consistent series, and changing definitions of observed series. The measurement of money leads directly to the calculation of its opportunity cost, in Section IV.2.

The concept of money is imprecise and ambiguous, and has been so for decades. In their evidence to the U.K. Royal Commission on the Values of Gold and Silver, Marshall and Edgeworth cited important changes contributing to these difficulties: the newly introduced checkbook, more rapid transfers between bank accounts in different 
locations due to the telegraph, and bimetallism itself through the respective quantities and prices of gold and silver. The first and third factors affected the definition of money itself, and all three factors allowed economization in the transactions medium. Later work has emphasized the changing importance of portfolio considerations versus liquidity.

Also, the very form of the transactions medium has changed greatly, becoming interest bearing (for the most part) towards the end of the sample. While cash may not have changed much, its substitutes have. Checks have fallen from favor relative to credit cards, and recently debit card transactions have grown rapidly. The recorded measures of money also have changed over the period, especially the coverage of the most cited measures - M0, M1, M2, M3, and M4. ${ }^{5}$ In particular, building societies (akin to savings and loans associations) have grown rapidly, offering close substitutes for commercial-bank liabilities, and with some building societies converting their legal status to commercial banks from 1989 onwards. Hendry and Ericsson (1991a, pp. 3234) highlighted such reservations on the measurement and interpretation of $M$.

These difficulties and their consequences are apparent in the series for money used herein. Both Friedman and Schwartz (1982) and Attfield, Demery, and Duck (1995) were faced with incomplete series on any measure of broad money over their samples. The measure M2 ("old definition") exists through 1971; M3 from 1963 though 1987; and M4 (adjusted for slight definitional breaks) from 1982 through 1993. To create their annual money series, Friedman and Schwartz (1982, p. 114) spliced M3 onto M2, multiplying M3 by approximately 0.996 to match the value of M2 in 1968 and using that rescaled M3 from 1969 through 1975. To extend the data through 1993, Attfield, Demery, and Duck (1995, Data Appendix) similarly spliced M4 onto M3 in 1987, with M4 multiplied by approximately 0.545. Attfield, Demery, and Duck also spliced M0 onto Friedman and Schwartz's measure of high-powered money $H$ in 1975, with M0 being multiplied by approximately 1.27 .

\footnotetext{
${ }^{5}$ The key measures of money discussed herein are high-powered money, M0, M1, M2, M3, and M4, which are ordered (more or less) from the narrowest measure to the broadest measure. These measures are defined in brief below; details appear in Ericsson, Hendry, and Prestwich (1997). High-powered money $H$ is the sum of "currency outside banks, currency held by banks, bankers' deposits, special deposits, and private deposits at the Bank of England" [Friedman and Schwartz (1982, p. 137)]. Attfield, Demery, and Duck (1995) spliced together $H$ and the monetary base M0, which is notes and coins in circulation outside the Bank of England plus banks' operational deposits with the Bank of England. The measure M1 is notes and coins in circulation with the public plus sight bank deposits (i.e., current accounts or, equivalently, checking accounts). If interest-bearing sight deposits are excluded from M1, the resulting measure is non-interest-bearing M1 (NIB M1). The measure of M2 in Friedman and Schwartz (1982, pp. 134-135) is total M1 plus deposit accounts (time deposits) at deposit banks and discount houses. The measure M3 is M2 plus all other bank deposits. The deposits in M3 are of U.K. residents only; those in M1 and M2 are of private sector residents only and sterling-denominated. The measure M4 is the sterling-denominated component of M3 plus (essentially) private sector holdings of shares, deposits, and sterling certificates of deposit at building societies.
} 

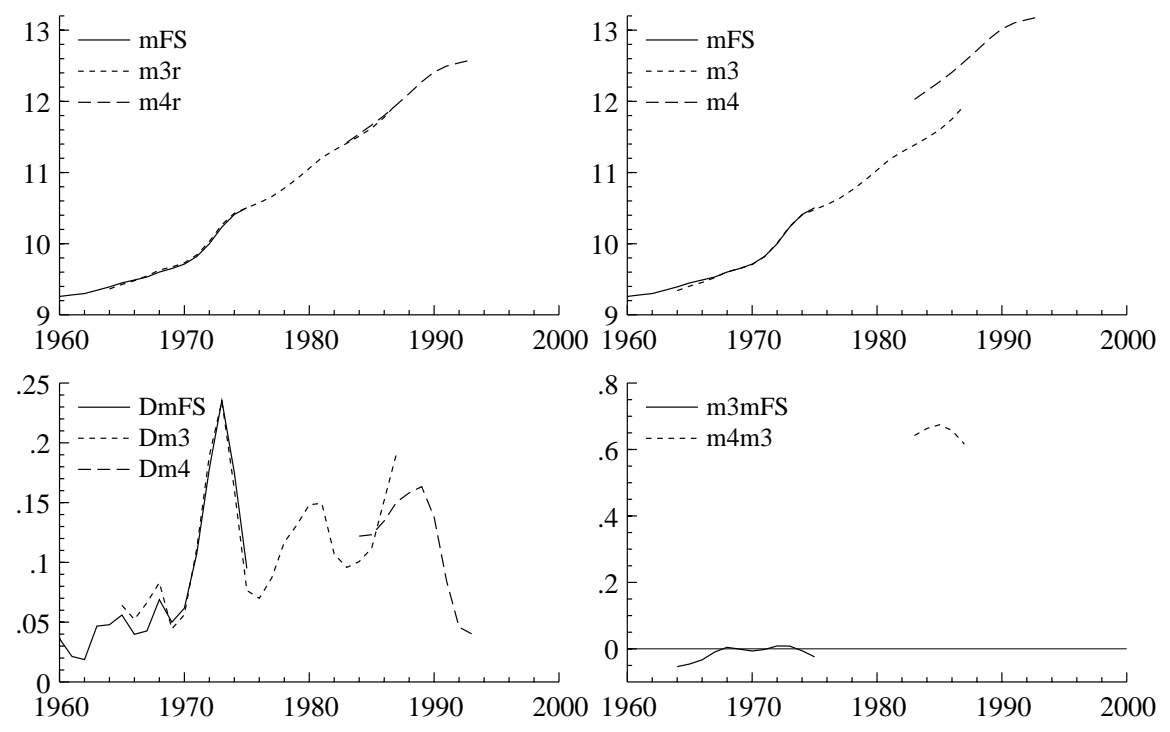

Figure 4: Logs of rescaled money, logs of unrescaled money, growth rates of unrescaled money, and logs of the ratios of unrescaled money for overlapping periods.

The statistical magnitudes of the splicings for $M$ are apparent from Figure 4, which plots the logs of $M$ [as from Friedman and Schwartz (1982)], rescaled M3, and rescaled M4 (Figure 4a); the logs of Friedman and Schwartz's $M$ and the unrescaled M3 and M4 (Figure 4b); the growth rates of the three measures (Figure 4c); and logs of the ratios of the series for periods with overlapping observations (Figure $4 \mathrm{~d}$ ). The first splice in $M$ appears minor in nature. The second, by contrast, markedly broadens the definition of money, with M4 being 1.83 times M3 in 1987, the date of the second splicing. The non-M3 component of M4 (dominated by building society deposits) is almost entirely interest-bearing, so the implicit opportunity cost on the spliced money series is nearly halved, leading to the discussion in the next subsection.

\section{IV.2 The Opportunity Cost of Holding Money}

Because older series such as M2 and M3 and some of their components are not published for the latter part of the sample, construction of a "consistent" series is infeasible, so modelers are left with little option other than splicing series together. However, splicing may alter the implied opportunity cost of holding the (measured) money, with the second splice being of primary concern because of the numerical magnitudes involved. The choice of measured opportunity cost in turn can dramatically affect the performance of empirical models of money demand. Thus, this subsection re-examines existing measures of the opportunity cost. They prove inadequate, so 
we develop a modified measure of the opportunity cost, which is key to the empirical constancy of (5) when the data are extended through 1993.

Friedman and Schwartz (1982) and Hendry and Ericsson (1991a) propose two different measures of the opportunity cost for $M$. Hendry and Ericsson (1991a) use the short-term interest rate $R S$ as the primary opportunity cost of holding money, as in (3), (4), and (5) above. Friedman and Schwartz (1982) advocate using a fraction of $R S$, denoted $R N$ and calculated as $(H / M) \cdot R S$. This alternative measure assumes that all components of $M$ except for high-powered money $H$ earn interest at the (outside) short-term rate $R S$. Three issues bear on the choice between $R S$ and $R N$ and on the suitability of either as an opportunity cost: the ratio $H / M$, the relationship between the actual own rate and $R S$, and the measures of $H$ and $M$ for calculating $R N$.

First, if $H / M$ is nearly constant, empirical results should be relatively unaffected by the choice between $R S$ and $R N$, aside from a scale factor on the estimated coefficient. For Friedman and Schwartz's sample period, $H / M$ varies almost exclusively within the narrow range $[0.22,0.28]$. As Hendry and Ericsson (1991a, p. 32, footnote 26) note, their annual models are little affected by those choices of interest rate.

Second, if the relationship between $R S$ and the own rate of interest changes, neither $R S$ nor $R N$ may be good proxies for the actual opportunity cost. Hendry and Ericsson (1991a) expressed this concern, particularly because the behavior of the own interest rate did change at the end of Friedman and Schwartz's sample.

A potential explanation ..., consistent with the earlier evidence and economic analysis, is presaged by Klovland's (1987) result for pre-1914 data that the own interest rate on broad money is an important omitted variable from the present information set. ... Over much of the sample, U.K. commercial banks acted like a cartel with administered (and generally low) deposit interest rates; this situation changed after 1970 due to the competition regulations [i.e., CCC]. Thus, own interest rates rose rapidly, altering the historical differentials and inducing predictive failure in models that excluded that variable. (p. 32)

Third, constructed $R N$ may use either spliced or unspliced high-powered money and broad money. In Friedman and Schwartz's framework, proper measurement of $R N$ requires the unspliced data, even while the modeled money series is spliced. By way of explanation, note that the second splice itself sharply decreases the percentage of (spliced) money not bearing interest. That percentage is measured by the ratio of unspliced high-powered money to unspliced broad money. To distinguish between measures using spliced and unspliced series, $H$ and $M$ denote spliced series, whereas $H^{a}$ and $M^{a}$ denote actual values (superscript ${ }^{a}$ for actual). Specifically, $H^{a}$ and $M^{a}$ are not rescaled for the definitional changes in 1975 (for $H$ ) and 1987 (for $M$ ). 


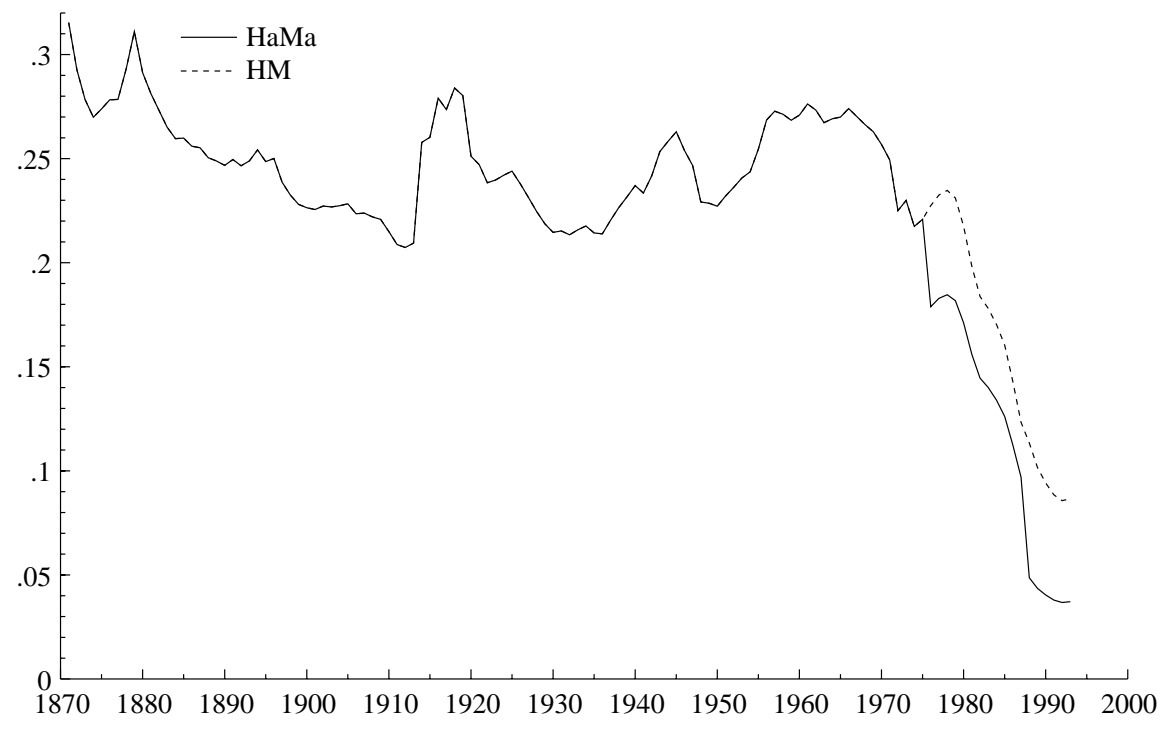

Figure 5: Time series of the ratios $H^{a} / M^{a}$ and $H / M$.

Correspondingly, $R N$ denotes $(H / M) \cdot R S$ (as above) with spliced series, and $R N^{a}$ denotes $\left(H^{a} / M^{a}\right) \cdot R S$.

Figure 5 shows the time series of $H^{a} / M^{a}$ and $H / M$. The ratio $H^{a} / M^{a}$ changes little over the period prior to 1970, but falls sharply and rapidly to near zero over 1971-1993. The two largest drops in $H^{a} / M^{a}$ occur from redefinitions: in 1976, when $H$ switches from high-powered money to M0, with a rescaling of 0.787 ; and in 1988 , when $M$ switches from M3 to M4, with a rescaling of 1.83 . These effects play an important role in explaining the mis-predictions of the mechanically updated annual model (6), as Section V.1 shows. The ratio $H / M$ equals $H^{a} / M^{a}$ through 1975 , with $H / M$ increasing over 1976-1978 while $H^{a} / M^{a}$ declines. The ratio $H / M$ then falls throughout the remainder of the sample, with its differential relative to $H^{a} / M^{a}$ widening after 1987. Differences in the empirical consequences from using $R S, R N$, and $R N^{a}$ are thus most likely to be detectable on the recent data.

\section{IV.3 Financial Innovation and Financial Deregulation}

The last century has witnessed considerable financial innovation. Examples early in the sample include the telegraph, the checkbook, and building societies. More recent examples include interest-bearing sight deposits, credit cards, and cash machines. All have combined to alter the financial scene radically. In particular, they have changed the role of money as an asset in portfolios, as a source of liquidity, and as the main component of the transactions medium. 
Financial deregulation has played a pivotal role as well, both by allowing some forms of financial innovation to occur and by allowing rates of return on existing assets to be determined in a more competitive atmosphere. This subsection considers three key deregulations affecting the latter part of the sample: Competition and Credit Control, the allowance of interest-bearing sight deposits, and a 1986 Act of Parliament. Section IV.4 and Section V discuss how to account for innovation and deregulation in the model.

As the quote in Section IV.2 notes, in 1971 Competition and Credit Control deregulated the commercial banking sector, abolishing the earlier cartel arrangements. CCC reduced credit rationing and led to an otherwise unexplained increase in money holdings, which Hendry and Ericsson (1991a) modeled using the dummy variable $D_{4}$. For earlier attempts at accounting for this change, see Hacche (1974), Hendry and Mizon (1978), and Lubrano, Pierse, and Richard (1986) inter alia.

Financial deregulation in 1984 permitted retail sight deposits (checking accounts) to bear interest. The opportunity cost of holding narrow money fell substantially, and the demand for (e.g.) M1 increased correspondingly, as shown in Hendry and Ericsson (1991b). The increase in M1 is large, e.g., 129\% in nominal M1 (86\% in real M1) between 1984Q3 and 1989Q2.

During 1986-1989, additional financial deregulation loosened credit rationing, particularly for building societies, following the U.K. Parliament's 1986 Building Societies Act. See Muellbauer (1994) for a discussion of the Act's large effects on consumers' expenditure. Given the similarities between the deregulations of the 1970s and the 1980s, the dummy $D_{c}$ includes both episodes.

\section{IV.4 Constancy}

As Judd and Scadding (1982) document, constancy is a critical and often elusive feature of empirical money-demand equations. Indeed, the historical review in Hendry (1996) shows that constancy has long been regarded as a fundamental requirement for empirical modeling generally, since models with no constancies cannot be used for forecasting, analyzing economic policy, or testing economic theories. Equally, model evaluation is central to any progressive research strategy: retrospective evaluations are particularly valuable for learning about the evolution of the economy and how to improve the performance of existing empirical models.

This subsection thus analyzes statistical implications for a model's constancy over an extended sample with financial innovation and changed data definitions and opportunity costs. To do so, it helps to formalize the concept of constancy for econometric equations fitted to time series. Briefly, suppose a parameter $\theta$ indexes a stochastic process: by definition, $\theta$ is constant across realizations of that process. Even so, $\theta$ may vary over time, perhaps depending on other stochastic processes. If $\theta$ has the same value throughout the period $\mathcal{T}$, then $\theta$ is constant over that period. A model is 
constant over $\mathcal{T}$ if all of its parameters are constant over $\mathcal{T}$ : see Hendry (1995, pp. 32, 355). Hendry (1996) highlights important ambiguities for constancy concerning parameterization and model formulation. This subsection and Section IV.5 draw on and expand upon that analysis, illustrating some of the subtleties involved through five examples with a simple conditional linear model.

Constancy of a model depends upon how the model is formulated and upon how its variables are updated for extended samples. In particular, constancy may depend upon inclusion in the model of data that are zero over the initial sample. Five forms of a simple conditional linear model aid in discussing this and related aspects of constancy:

$$
\begin{array}{rlrl}
\text { Initial Model } y_{t} & =\theta^{\prime} z_{t}+\varepsilon_{t} & t=1, \ldots, T_{1} \\
\text { Isolikelihood Model } y_{t} & =\theta^{\prime} z_{t}+\delta^{\prime} w_{t}+\varepsilon_{t} & t=1, \ldots, T \\
\text { Expanded Model } & y_{t} & =\theta^{\prime} z_{t}+\gamma^{\prime} Q w_{t}+\varepsilon_{t} & \\
\text { Reparameterized Model } & y_{t} & =\theta^{\prime}\left(z_{t}+A Q w_{t}\right)+\left(\gamma^{\prime}-\theta^{\prime} A\right) Q w_{t}+\varepsilon_{t} \\
\text { Translated Model } & y_{t} & =\theta^{\prime}\left(z_{t}+A^{*} Q w_{t}\right)+\varepsilon_{t} & \\
& & =\theta^{\prime} z_{t}^{*}+\varepsilon_{t} .
\end{array}
$$

In the initial model (7), the variable $y_{t}$ depends linearly on $k$ variables $z_{t}$ with coefficient vector $\theta$ and error $\varepsilon_{t}$ over the initial sample $\left[1, T_{1}\right]$. Here and elsewhere, a prime' transposes a vector or matrix. In the remaining four models, the data period is extended to include $K$ more observations $\left[T_{1}+1, T\right]$. In the second or isolikelihood model (8), the initial model is extended to include $K$ variables $w_{t}$ that are zero over $\left[1, T_{1}\right]$, linearly independent over $\left[T_{1}+1, T\right]$, and with an arbitrary coefficient vector $\delta$. This second model has the same likelihood value as the initial model (7).

The variables $w_{t}$ might enter the isolikelihood model as some subset of $K$ nonsingular linear combinations of $w_{t}$ - e.g., as $Q w_{t}$, for some known full-rank matrix $Q$. If $w_{t}$ does so, this generates the expanded model (9), where $Q w_{t}$ has some coefficient vector $\gamma$. The expanded model always can be rewritten as the reparameterized model (10), which depends upon some linear combination $(I: A)$ of $\left(z_{t}: Q w_{t}\right)$ with coefficient $\theta$, and upon $Q w_{t}$ itself. Finally, a specific linear combination of $\left(z_{t}: Q w_{t}\right)$ may exist $\left[\left(I: A^{*}\right)\right.$, say] such that the reparameterized model depends on that linear combination alone and not additionally on $Q w_{t}$ per se. If such a linear combination exists, the resulting translated model is (11), so-called because $z_{t}$ has been translated into $z_{t}^{*}\left(=z_{t}+A^{*} Q w_{t}\right)$ over the extended sample. Thus, the expanded and reparameterized models provide a bridge from the initial and isolikelihood models to the translated model. Five examples help clarify the interpretation of these models.

Example 1: The Chow statistic for testing predictive failure. The initial model (7) and the isolikelihood model (8) are the basis of Chow's (1960) statistic for testing predictive failure. Without loss of generality, suppose that $w_{t}$ is a set of zeroone impulse dummies: specifically, $K$ dummies for the $K$ observations in $\left[T_{1}+1, T\right]$. 
By construction, the coefficient vector $\theta$ on $z_{t}$ remains unchanged as the sample and model expand from (7) to (8); and (7) and (8) are identical over the initial subsample. The $F$-statistic testing that $\delta=0$ is simply the Chow statistic for predictive failure; see Salkever (1976). That is, the Chow statistic tests whether or not extending the sample requires extending the model relative to the initial measurements $\left\{y_{t}, z_{t}\right\}$.

If $\delta=0$, lengthening the sample does not require any extension of the model. This is the "purest" form of model constancy. Conversely, for any initial model (7), $\theta$ is always unchanged over the extended sample $[1, T]$, provided the model is expanded by the $K$ dummies $w_{t}$ with arbitrary weights $\delta$. This constancy of $\theta$ is trivial in that constancy holds by construction.

Example 2: A reduced set of additional variables. The expanded model (9) provides a testably simpler representation of the isolikelihood model (8). Suitable choice of $Q$ in (9) can generate any time series over $\left[T_{1}+1, T\right]$. For $Q$ of rank less than $K$, only certain linear combinations of $w_{t}$ are relevant over the extended sample, thus simplifying or reducing (8) to (9). For instance, (5) above extends (3) by 5 observations but uses only 2 additional variables to do so: $D_{4 t}$ and $D_{4 t} \cdot \Delta r s_{t}$.

Example 3: The measurement of money. Section IV.1 discusses how the measurement of money alters over the sample. That is, $y_{t}$ is translated into some new variable $y_{t}^{*}$, much as $z_{t}$ is translated into $z_{t}^{*}$ above. Equation (9), with known $\gamma$ and $Q$, includes translations of $y$ as a special case, with $y_{t}^{*}=y_{t}-\gamma^{\prime} Q w_{t}$. For translated $z$, though, $A$ (and $A^{*}$ ) and $Q$ generally are known, whereas $\gamma$ is estimated.

Example 4: Financial innovation and interest rate spreads. Achieving a translated model requires both a reduction from $w_{t}$ to $Q w_{t}$ to achieve (9), and the restriction that $\gamma^{\prime}=\theta^{\prime} A$ to obtain (11). The empirical modeling of U.K. M1 in Hendry and Ericsson (1991b) and Hendry (1996) illustrates such simplifications.

Specifically, suppose $T_{1} \approx 1984, y$ is nominal M1 in the United Kingdom, $z$ is the Local Authority 3-month deposit rate $R^{L A}$ (the outside rate for M1), $Q w$ is the interest rate on sight deposits $R^{S D}$ (the own rate of $\mathrm{M} 1$ ), and other variables in the relationship are ignored for ease of exposition. Hendry and Ericsson (1991b) and Hendry (1996) demonstrate the constancy through 1984 of a pre-existing model for U.K. M1, where that model includes $R^{L A}$ but not $R^{S D}$. Over 1985-1989, that model fails miserably on Chow's statistic. By construction, and trivially, the original parameters of that model are constant if a dummy is added for each observation in the forecast period, giving (8). More interestingly, the initial model remains constant if just $R^{S D}$ is added to it. That is, the expanded model (9) is such that $Q w_{t}=R_{t}^{S D}$. Finally, $\gamma=-\theta$ is a statistically acceptable restriction, implying that the interest rate differential $R^{L A}-R^{S D}$ is a suitable translation of the original variable $R^{L A}$, resulting in (11) with $A^{*}=-1$. Importantly, the translated model has the same parameter as the initial model: only the measurement of the data changes, and that, only for the extended portion of the sample.

Constancy is an operational concept for both the expanded and translated models. 
Both are testably constant over the whole sample period, i.e., relative to the isolikelihood model. Furthermore, the corresponding tests are interpretable as encompassing tests of the additional information in the forecast period.

Economically, the introduction of interest-bearing sight deposits requires redefining the opportunity cost of holding transactions money. Initially, the opportunity cost is the outside interest rate $R^{L A}$. Once sight deposits begin earning interest, the opportunity cost becomes the differential with the own rate, i.e., $R^{L A}-R^{S D}$. Equally, the opportunity cost is the differential $R^{L A}-R^{S D}$ for the full sample, and that measure is observationally equivalent to the outside rate $R^{L A}$ over the initial subsample. Similar examples arise for numerous other countries. In particular, see Baba, Hendry, and Starr (1992) for the United States and Ericsson and Sharma (1996) for Greece.

Example 5: The measurement of opportunity cost. Section III and Section $\mathrm{V}$ empirically analyze a similar issue in the measurement of the opportunity cost for the annual data on broad money demand. The current example sets up the algebra of constancy for that analysis.

Suppose $T_{1}=1975 ; y$ is nominal broad money $m ; z$ is the short-term interest rate $R S$, which is the interest rate in (4); $Q w$ is $\left(1-\frac{H^{a}}{M^{a}}\right) \cdot R S$, which is the own rate on $M$ proposed in Section IV.2 and based on Friedman and Schwartz (1982); and $A^{*}=-1$. For ease of presentation, other variables in the relationship are ignored (as in Example 4), and $B$ is defined as the term $\left(1-\frac{H^{a}}{M^{a}}\right)$ in the proposed own rate. Because this example is central to Sections III and V, and because it is somewhat more complicated than Example 4, the five model representations are written explicitly:

$$
\begin{aligned}
& \text { Initial Model } m_{t}=\theta R S_{t}+\varepsilon_{t} \quad t=1, \ldots, T_{1} \\
& \text { Isolikelihood Model } m_{t}=\theta R S_{t}+\delta^{\prime} w_{t}+\varepsilon_{t} \quad t=1, \ldots, T \\
& \text { Expanded Model } m_{t}=\theta R S_{t}+\gamma B_{t} R S_{t}+\varepsilon_{t} \\
& \text { Reparameterized Model } m_{t}=\theta\left(R S_{t}+A \cdot B_{t} R S_{t}\right)+(\gamma-\theta A) B_{t} R S_{t}+\varepsilon_{t}(15) \\
& \text { Translated Model } m_{t}=\theta\left(R S_{t}-B_{t} R S_{t}\right)+\varepsilon_{t} \\
& =\theta R N_{t}^{a}+\varepsilon_{t} \text {. }
\end{aligned}
$$

Hendry and Ericsson (1991a) demonstrate the constancy through 1975 of the initial model (12), which is (5) in conjunction with (4). Using the Chow statistic implied by (13), Section III.2 shows that this initial model is nonconstant on the sample extended through 1993. However, model translation recovers constancy. Section V below shows that the coefficients in the initial model remain constant if two variables are translated: $R S$ into $R N^{a}$, as from (12) to (16); and $D_{4}$ into $D_{c}$, which follows from a similar model path. Paralleling Example 4, the translated model (16) has parameters equivalent to those in the initial model (12): only the measurement of the data changes.

Because $B_{t} R S_{t}$ is actually nonzero over the whole sample and not just over $\left[T_{1}+1, T\right]$, the empirical basis for this example is slightly more complicated than 
that given in (12)-(16). The ratio $H^{a} / M^{a}$ is nearly constant through 1975 (Figure 5), so $R S$ and $R N^{a}$ are virtually indistinguishable over that period, aside from a scale factor (see Figure $6 \mathrm{~b}$ below). The parameter $\theta$ in the initial model (12) is thus the coefficient on the opportunity cost $R N^{a}\left(=R S \cdot H^{a} / M^{a}\right)$, multiplied by the (near constant) value of $H^{a} / M^{a}$ over that subsample. As $H^{a} / M^{a}$ falls in the late $1970 \mathrm{~s}$ and the 1980s, the measure of opportunity cost $R N^{a}$ accounts for that fall, as in (16). With $R S$ alone, the model breaks down. Mis-measurement of $R N^{a}$ by $R N$ also can induce predictive failure because $H^{a} / M^{a}$ and $H / M$ behave differently over the last two decades of data; see Figure 5.

\section{IV.5 General Remarks}

This subsection considers several related issues: time-varying coefficient models, the consequences of nonsingular reparameterizations and data transformations, tests of constancy, data redefinitions, and Divisia indexes.

First, constant models can have time-varying coefficients, provided a deeper set of constant parameters characterizes the data generation process. Examples include the structural time-series models in Harvey (1981) and Harvey and Shephard (1993), random-coefficients models, and the smooth transition dynamic models in Teräsvirta and Anderson (1992) and Granger and Teräsvirta (1993). Example 5 above also falls into this category, in that $\theta\left(1-B_{t}\right)$ in (16) varies over time even though $\theta$ does not. Thus, the existence of constancy may depend on whether raw coefficients or underlying parameters are evaluated.

Second, since one-to-one transformations of parameters are also valid parameters, zero can be the population value for some parameters in an equivalent representation. Consequently, the definition of model constancy above allows for an expanded model, provided that the existing parameters stay constant. Relatedly, there is often a choice between nearly equivalent variables at various stages of empirical modeling, with subsequent data clarifying which variables actually determine a sustainable relationship. Example 5 illustrates this point with $R S$ and $R N^{a}$.

Third, no tests could exist in-sample (i.e., using only information up to $T_{1}$ ) for whether an empirical model will manifest predictive failure out of sample. An insample test correctly indicating the failure of the initial model would incorrectly indicate the failure of a (constant) translated model, as the initial model is identical to the translated model in-sample. Consequently, predictive failure is uniquely a postsample problem, requiring change somewhere to induce change elsewhere. Hence, models should not be selected on the basis of their forecast performance unless their sole purpose is forecasting. Clements and Hendry (1996) show that forecasting models can be robustified against important forms of predictive failure by intercept corrections or differencing; see also Hendry and Mizon (1996).

Fourth, previous experience with updating models of money demand and of con- 
sumers' expenditure has revealed many pitfalls, including redefinitions of variables, large changes in measurements between data revision vintages, and important structural changes; see Hendry and Ericsson (1991b) and Hendry (1994) respectively for examples. In the present context, many measures of money exist, their definitions and coverages have altered over time, and the principal measure in Friedman and Schwartz (1982) (namely M2) ceased to be the appropriate one for the United Kingdom and was replaced by M3 and then by M4. The measure M4 (but not M2 or M3) includes the liabilities of building societies and seems the most appealing as a measure of broad money; see Hendry and Ericsson (1991a, Data Appendix). These changes in measured money require adaptations elsewhere in the model. This section has focused on the most obvious adaptation, that for the measured opportunity cost of money itself. Coherent measurement of the opportunity cost (and of data generally) is contextual rather than absolute, in that the measurement may differ depending upon the economic relationship being modeled.

Fifth, to address issues such as deregulation and financial innovation, some researchers have sought to develop better indices of money, weighting money's components by their "liquidity". In Divisia indices, for example, the liquidity of a component of money is inversely related to the corresponding rate of return; see Diewert (1976), Barnett (1980), and la Cour (1996). We do not follow this route because Divisia indexes per se seem unlikely to resolve the changes that occurred. For instance, the relevant rates of return were controlled over some subsamples and deregulated over others. A Divisia approach implies (implausibly) that liquidity suddenly changes when interest rates move upon deregulation, even when the quantities of an aggregate's components and the characteristics of those components (other than their rates of return) remain unchanged. Furthermore, mortgage rationing was prevalent over most of the 20th century in the United Kingdom, with building societies offering high interest rates on their (highly liquid) deposit and share accounts; see Anderson and Hendry (1984) and Muellbauer (1997).

\section{An Economic Extension of the Annual Model}

This section re-analyzes the annual model (5) over the extended sample. With the statistical measures of opportunity cost and deregulation adjusted to reflect the economic concepts that they attempt to capture, the annual model's coefficients remain constant over the two decades of the forecast period. Section V.1 examines longrun properties first and the dynamic equilibrium correction model subsequently, as in Hendry and Ericsson (1991a). Sections V.2 and V.3 focus respectively on the identification of the model as a money demand equation and on the model's policy implications. 


\section{V.1 Constancy of an Economic Extension of the Model}

In the annual model (5) with (4), the measure of opportunity cost is $R S$ and so does not incorporate the definitional and institutional changes described in Section IV, which occur primarily after 1975 . To address these changes, $R S$ is replaced by $R N^{a}$, which leaves the estimates in (5) and (4) virtually unaffected. To show the value of model translation, (4) and (5) are each estimated with $R N^{a}$ rather than $R S$, first over their initial sample and then over the extended sample. For ease of comparison between coefficients on $R S$ and $R N^{a}, R N^{a}$ is divided by 0.25 , the approximate mean of $H^{a} / M^{a}$ for the sample 1878-1975. ${ }^{6}$ This subsection finishes by estimating the economic extensions of (4) and (5) jointly by nonlinear least squares.

Using $R N^{a}$ rather than $R S$ to measure the opportunity cost, the Engle-Granger regression (4) becomes:

$$
\begin{gathered}
(m-p-i)_{t}=-0.318-6.67 R N_{t}^{a} \\
T=98[1873-1970] \quad R^{2}=0.59 \quad \hat{\sigma}=10.57 \% \quad d w=0.31 \quad t_{A D F}=-2.77,
\end{gathered}
$$

which mirrors the results in (4). ${ }^{7}$ The residuals from (17) provide the equilibrium correction term $\tilde{u}_{t}$, which proxies for long-run excess demand and replaces the residual $\hat{u}_{t}$ from (4). Figure 6a plots the two residuals $\left(\hat{u}_{t}\right.$ and $\left.\tilde{u}_{t}\right)$ through 1970. Figure 6b plots the corresponding measures of opportunity cost $\left(R S\right.$ and $\left.R N^{a}\right)$ over the same period. The differences between the old and new measures are minor in both graphs. Figures $6 \mathrm{c}$ and $6 \mathrm{~d}$ plot the same series on the new sample: both of these graphs show marked differences between the old and new measures, as implied by $H^{a} / M^{a}$ in Figure 5 .

The translated model is (17) estimated over the full sample:

$$
\begin{gathered}
(m-p-i)_{t}=-0.344-6.30 R N_{t}^{a} \\
T=121[1873-1993] \quad R^{2}=0.63 \quad \hat{\sigma}=11.73 \% \quad d w=0.42 \quad t_{A D F}=-4.68^{* *} .
\end{gathered}
$$

Equation (18)'s coefficients and fit hardly differ from those of (4) and (17), and the additional data more clearly confirm cointegration.

Following Hendry and Ericsson (1991a), regression residuals from either (17) or (18) could enter as the equilibrium correction term in the dynamic equation. Equation (17) has the advantage that its sample pre-dates the forecast period. Conversely,

\footnotetext{
${ }^{6}$ Because the data here are annual rather than (e.g.) quarterly, we have not attempted to adjust $R N^{a}$ for agents' learning of financial innovations; cf. Hendry and Ericsson (1991b) and Baba, Hendry, and Starr (1992).

${ }^{7}$ To parallel the approach in Hendry and Ericsson (1991a), this section presents Engle-Granger regressions rather than (say) the cointegration analysis in Johansen (1995) based on vector autoregressions. We intend to report such an analysis at a later date for the complete system of money, prices, income, and interest rates. A subsystem analysis appears in Ericsson and Irons (1995b).
} 

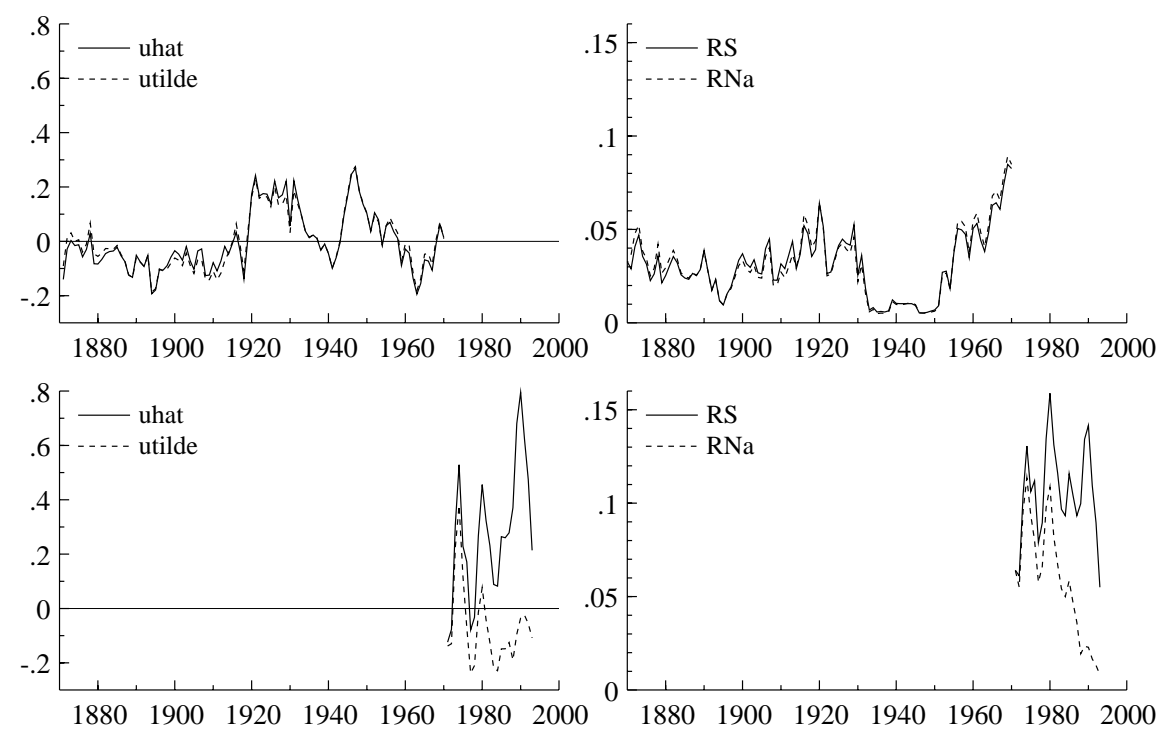

Figure 6: Cointegration residuals $\hat{u}$ and $\tilde{u}$ using $R S$ and $R N^{a}$ respectively, plotted over subsamples, and the corresponding values for $R S$ and $R N^{a}$.

assuming that the relation does cointegrate, (18) should be more precisely estimated than (17). In practice, the choice makes little difference, and (17) is used below.

With $R N^{a}$ as the opportunity cost measure in the cointegrating relation, the sample to 1973 delivers the following re-estimated dynamic model, paralleling (5):

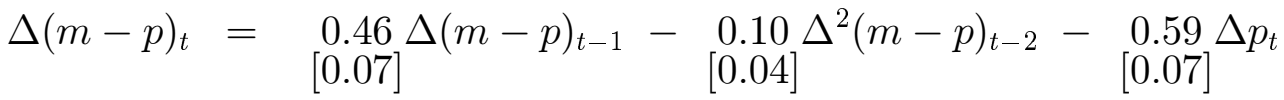

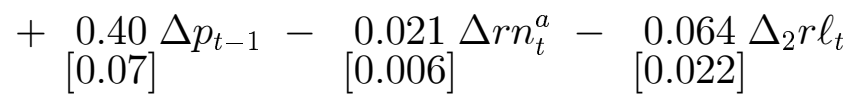

$$
\begin{aligned}
& -\underset{[0.62]}{2.83}\left(\tilde{u}_{t-1}-0.2\right) \tilde{u}_{t-1}^{2}+\underset{[0.002]}{0.004}+\underset{[0.7]}{3.7}\left(D_{1}+D_{3}\right)_{t} \\
& +\underset{[1.6]}{6.4 D_{4 t}}+\underset{[0.078]}{0.094 D_{4 t} \cdot \Delta r s_{t}} \\
& T=96[1878-1973] \quad R^{2}=0.88 \quad \hat{\sigma}=1.406 \% \quad d w=1.89 \\
& A R: F(2,83)=1.14 \quad \text { ARCH }: F(1,83)=1.40 \quad \text { Normality }: \chi^{2}(2)=0.7 \\
& \text { RESET }: F(1,84)=0.42 \text { Hetero }: F(18,66)=0.67 \quad \text { Form }: F(46,38)=0.74 \\
& J t=1.26 \quad \operatorname{Var}=0.08,
\end{aligned}
$$

where $\tilde{u}$ is from (17). The switch from $R S$ to $R N^{a}$ leaves the coefficients and $\hat{\sigma}$ in 
(19) virtually unaltered relative to those in (3) and (5). ${ }^{8}$

Estimation of (19) over the sample through 1993 obtains:

$$
\begin{aligned}
& \Delta(m-p)_{t}=\underset{[0.07]}{0.48} \Delta(m-p)_{t-1}-\underset{[0.04]}{0.10} \Delta^{2}(m-p)_{t-2}-\underset{[0.07]}{0.62} \Delta p_{t} \\
& +\underset{[0.07]}{0.40} \Delta p_{t-1}-\underset{[0.006]}{0.020} \Delta r n_{t}^{a}-\underset{[0.019]}{0.041 \Delta_{2} r \ell_{t}} \\
& -\underset{[0.46]}{2.26}\left(\tilde{u}_{t-1}-0.2\right) \tilde{u}_{t-1}^{2}+\underset{[0.002]}{0.004}+\underset{[0.6]}{3.9}\left(D_{1}+D_{3}\right)_{t} \\
& +\underset{[1.0]}{5.2} D_{c t}+\underset{[0.042]}{0.100 D_{4 t} \cdot \Delta r s_{t}} \\
& T=116[1878-1993] \quad R^{2}=0.87 \quad \hat{\sigma}=1.622 \% \quad d w=1.68 \\
& A R: F(2,103)=3.72^{*} \quad A R C H: F(1,103)=0.02 \quad \text { Normality }: \chi^{2}(2)=0.0 \\
& \text { RESET }: F(1,104)=1.35 \text { Hetero }: F(18,86)=0.90 \quad \text { Form }: F(52,52)=0.95 \\
& J t=1.93 \quad \text { Var }=0.82^{* *} \text {, }
\end{aligned}
$$

where the deregulation dummy $D_{4}$ has been extended as $D_{c}$ when entering by itself. In this translated model, the coefficients are virtually unaltered from the initial model (19), although $\hat{\sigma}$ has increased by about $15 \%$. Correspondingly, $J t$ is insignificant, whereas Var rejects. Consistent with this evidence, the covariance statistic for testing constancy of the coefficients over $1974-1993$ yields $F(10,95)=1.31$, whereas the Chow predictive-failure statistic is $F(20,85)=2.73^{* *}$. The latter has power to detect changes in equation error variances as well as in regression coefficients. An outlier in 1981 is primarily responsible for this rejection. Equally, rejection by the predictive-failure and Var tests reflects their high power to detect numerically modest changes in $\hat{\sigma}$. The long sample and the high variance of the data relative to that of the equation error are the proximate reasons for that high power.

Figures 7 and 8 summarize additional information on the performance of (19) and (20). Figure 7 graphs descriptive statistics for model (19): fitted, actual, and forecast values, plotted as time series and cross-plotted; the corresponding residuals; and the forecast and actual values, with \pm 2 standard error bands for the forecasts. Figure 7 for (19) parallels Figure 3 for (5). The dissimilar consequences of mechanistic and economic extensions of a model are apparent from comparison of Figure 3 and Figure 7, keeping in mind their markedly different scales. Figure 8 graphs the recursively estimated coefficients and plus-or-minus twice their recursively estimated standard errors (first nine panels), the 1 -step residuals and $0 \pm 2 \hat{\sigma}_{t}$, the 1 -step Chow

\footnotetext{
${ }^{8}$ Similar estimates result for the sample period extended through 1975 or truncated at 1970, the latter for the model without the two terms involving $D_{4}$; see Figure 8 below. We chose 1973 as the end point because it allows a minimal sample consistent with estimating the impact of CCC.
} 

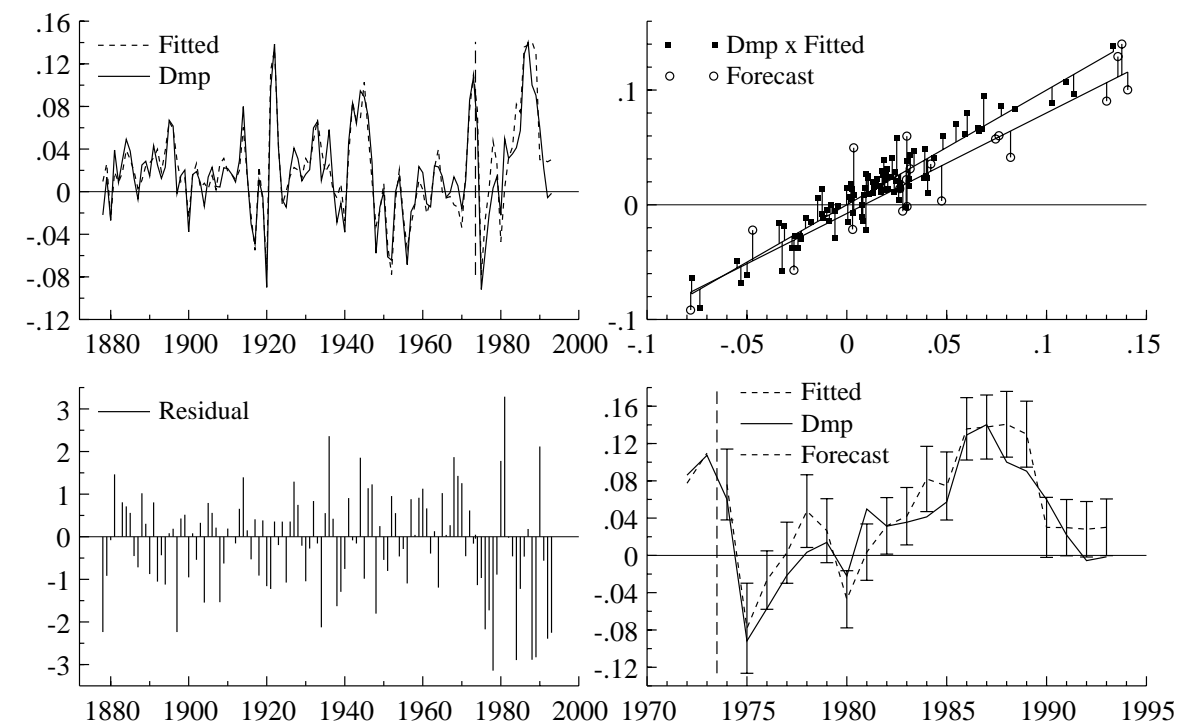

Figure 7: Fitted, actual, and forecast values of $\Delta(m-p)_{t}$ from (19), and their crossplots, corresponding scaled residuals, and forecasts with \pm 2 standard error bands.
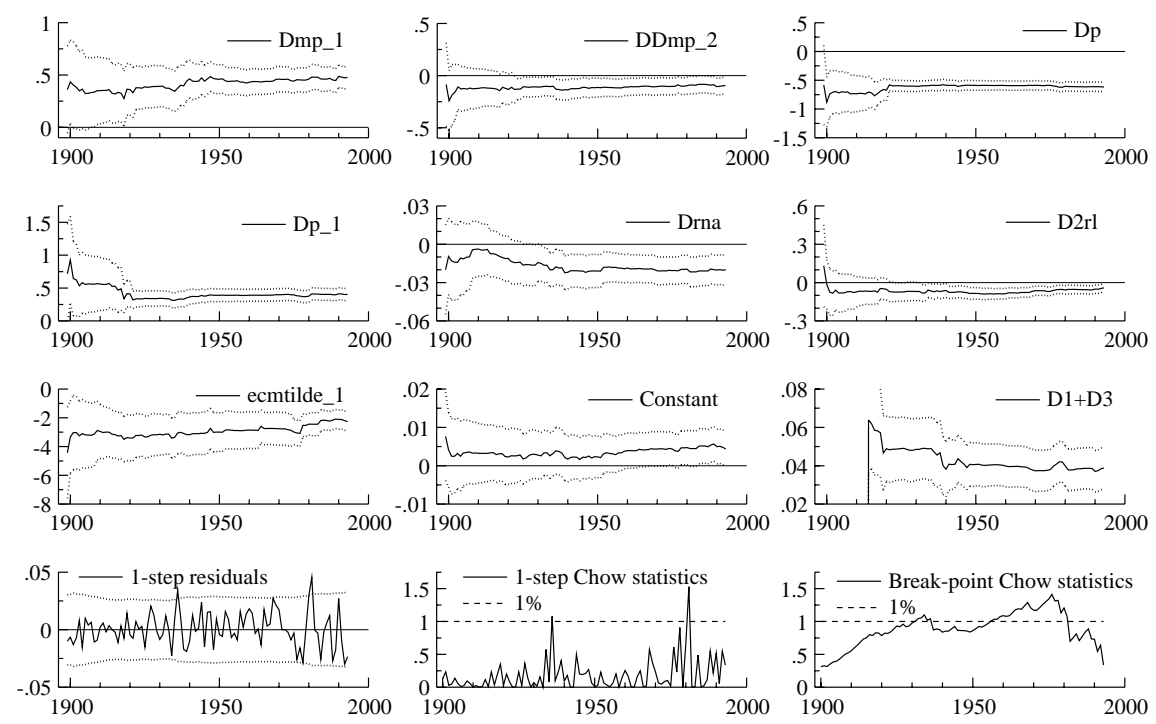

Figure 8: Recursive estimates for the first nine coefficients in (20), and the corresponding 1-step residuals, 1-step Chow statistics, and break-point Chow statistics. 
statistics normalized by their one-off $1 \%$ critical values, and the break-point Chow statistics likewise normalized, all for (20). ${ }^{9}$ From all of these graphs, the translated model (20) performs well over this turbulent period for the U.K. economy.

Equations (17) and (20) are together a single model, even though they are estimated sequentially. If (17) and (20) were estimated jointly, their coefficients would differ from those reported above, both because the dynamics in (20) would affect the estimates in (17) and because $\tilde{u}_{t}$ enters (20) nonlinearly. Joint estimation of the long-run and short-run parameters by nonlinear least squares obtains:

$$
\begin{aligned}
& \Delta(m-p)_{t}=\underset{(0.06)}{0.49} \Delta(m-p)_{t-1}-\underset{(0.04)}{0.10} \Delta^{2}(m-p)_{t-2}-\underset{(0.04)}{0.62} \Delta p_{t} \\
& +\underset{(0.05)}{0.41} \Delta p_{t-1}-\underset{(0.006)}{0.020} \Delta r n_{t}^{a}-\underset{(0.016)}{0.040} \Delta_{2} r \ell_{t} \\
& -\underset{(0.48)}{2.13}\left(\tilde{u}_{t-1}-\underset{(0.11)}{0.13}\right) \tilde{u}_{t-1}^{2}+\underset{(0.002)}{0.005}+\underset{(0.6)}{3.7}\left(D_{1}+D_{3}\right)_{t} \\
& +\underset{(0.7)}{5.4} D_{c t}+\underset{(0.028)}{0.090 D_{4 t} \cdot \Delta r s_{t}} \\
& T=116[1878-1993] \quad R^{2}=0.87 \quad \hat{\sigma}=1.620 \% \quad d w=1.77 \\
& A R: F(2,100)=2.80 \quad \text { ARCH }: F(1,100)=0.06 \quad \text { Normality }: \chi^{2}(2)=0.1 \\
& \text { Hetero : } F(21,80)=0.85 \text {, }
\end{aligned}
$$

where the equilibrium correction residual $\tilde{u}_{t}$ is now:

$$
\tilde{u}_{t}=(m-p-i)_{t}-\left(-\underset{(0.043)}{0.302}-\underset{(0.39)}{6.89} R N_{t}^{a}\right)
$$

The coefficients in (21) and (22) are little changed from those in (20) and (17), although the "interwar equilibrium departure" in the nonlinear equilibrium correction term is somewhat lower than previously, now being estimated at $+13 \%$ relative to the remainder of the period. No residual diagnostics are significant. Overall, the equilibrium correction model appears constant and well-specified on over a century of data, and the model confirms a nonlinear feedback reaction; see Escribano (1996).

Hendry and Ericsson (1991a) emphasized the role of constancy in their modeling approach.

Parameter constancy is at the heart of model design from both statistical and economic perspectives. Since economic systems are far from being constant and the coefficients of derived ("nonstructural" or "reduced

\footnotetext{
${ }^{9}$ Recursively estimated coefficients for $D_{c t}$ and $D_{4 t} \cdot \Delta r s_{t}$ are not displayed, given those variables' brief, transitory nature. Both sequences of Chow statistics are of the predictive-failure, rather than covariance, form.
} 
form") equations may change when any of the underlying parameters or data correlations change, it is important to identify empirical models that have reasonably constant parameters, which remain interpretable when change occurs. (p. 21)

Change in government policy rules is one obvious source of such change, and invariance of the estimated equation's coefficients to changes in policy rules is central to calculating the economic effects of those changes properly; see Section V.3 below. From Section IV, and in particular from Section IV.4, parameter constancy is compatible with (and may even require) economic extensions of the data and model. With the economic extensions for the opportunity cost of money and the proxy for deregulation, the EqCM in Hendry and Ericsson (1991a) remains constant over the additional two decades of data. Coherent rather than mechanical extensions are critical for obtaining that constancy.

\section{V.2 Identification of Money Demand}

The estimated relation, (17) plus (20), is interpreted as a money demand function for three reasons. First, being a conditional model, the parameterization of the demand function is unique. That conditional model arises from factorizing the joint distribution of money, prices, income, and interest rates into a (conditional) distribution for money conditional on prices, income, and interest rates, and a marginal distribution for prices, income, and interest rates. Given that factorization, the parameterization of the distribution of money is unique. Second, from institutional knowledge, the supply equation in the United Kingdom is an interest rate policy function, and it shifted substantially as economic policy regimes changed over the sample. Specific regimes include the Gold Standard and the policy of low interest rates during the interwar period. Consequently, any combination of the shifting supply function with the demand equation would be nonconstant, yet the estimated demand function is constant. In effect, these shifts in the supply function (over-)identify the demand function in the sense of the Cowles Commission. Third, the estimated coefficients have sensible interpretations as demand responses, but they are problematic in a policy reaction function. In particular, if the estimated equation is viewed as an inverted policy reaction function, it is difficult to understand why - or how - the Bank of England might seek to control the differential between the outside interest rate and the own interest rate.

The dummies for wars and credit deregulation complicate the issue of identification, as they might represent either supply perturbations or changed (unmodeled) conditions in money demand. The risks of wartime might induce additional money demand relative to usual opportunity costs, with the model implying a $3.9 \%$ increase in demand. Conversely, exigencies of financing war may have led to excessive printing of money. The equality of the coefficient across the two wars is more consistent 
with the former interpretation, given the changes induced by Keynes (1940), but is hardly definitive proof. Similarly, the proxy for deregulation could capture a shift in either demand or supply. Interpretation as a demand shift again seems preferable. Supporting evidence includes "round-tripping" (borrowing from a commercial bank to relend the money in the market at a higher rate) and withdrawal of housing equity (borrowing extra on a mortgage and redepositing some when the after-tax liquidity cost is low); see Green (1987) and Patterson (1993).

\section{V.3 Policy Implications}

Policy implications fall into (at least) three distinct categories, each involving a pair of related concepts: constancy and prediction, causation and endogeneity, and expectations and the Lucas (1976) critique. See Banerjee, Hendry, and Mizon (1996) for a general discussion.

First, parameter nonconstancy and predictive failure need not be germane to the policy under analysis if, for instance, the parameter nonconstancy or predictive failure arises from data mis-measurement. As shown above, mechanistic extension of a model can result in parameter nonconstancy and predictive failure, whereas economic extension of the same model can obtain constant parameters. So, parameter nonconstancy and predictive failure in themselves are not sufficient cause for discounting a model; see Hendry and Mizon (1996). Equally, econometric models may fit better than they forecast, simply because the proper economic extension is unknown ex ante. Predictive failure reflects a change somewhere in the structure of the economic

process during the forecast period. Conversely, models do not suffer predictive failure unless such change occurs.

That said, existing econometric models may provide information on the effects of future structural change. For example, in (20), the effect of the two World Wars on money demand are partialed out by using the dummy variables $D_{1}$ and $D_{3}$. Their coefficients are statistically insignificantly different from each other, so the effect on money demand from the First World War could predict in large measure the effect from the Second World War. A parallel result holds for the two major episodes of credit derationing, where both episodes have similar percentage effects on money demand.

Second, for the empirical models above, specific policy issues center on the direction of causation between money and prices. Does money growth cause inflation; or is it the converse, with inflation being responsible for increased money holdings? While causation cannot be wholly resolved from a single-equation study, Hendry and Ericsson (1991a) and Ericsson and Irons (1995a, 1995b) demonstrate super exogeneity of prices and interest rates in (3) and the non-invertibility of that conditional model; see also Engle and Hendry (1993). Those results carry over to (20). The evidence on super exogeneity and non-invertibility is consistent with a constant demand equation 
in which money is endogenously determined by private sector decisions, with policy determining the outside interest rate to which agents react.

Targeting the stock of an endogenous money stock could be problematic, especially if the demand for money depended on an interest rate spread or if the induced higher volatility in short-term interest rates increased the risk premium on long-term interest rates; see Sprenkle and Miller (1980) and Baba, Hendry, and Starr (1992). Both the Bank of England and the Federal Reserve Board targeted various monetary aggregates during the late 1970s and early 1980s. Both experienced difficulties in achieving the set targets, and both eventually abandoned monetary targeting. In testimony to the Joint Economic Committee of the U.S. Congress, Paul Volcker (1982), the then Chairman of the Board of Governors of the Federal Reserve System, is particularly explicit about those difficulties.

As you are aware, the current job of developing and implementing monetary policy has been complicated by regulatory decisions as well as by recent developments in the economy and in our financial markets. We have as a consequence (1) made some technical modification in our operating procedures to cope with obvious distortions [due to the introduction of interest-bearing checking accounts] in some of the monetary data, particularly M1, and (2) accommodated growth in the various monetary aggregates at rates somewhat above the targeted ranges. The first of those decisions was essentially technical. The latter decision is entirely consistent with the view I expressed in testifying before the Banking Committees in July [1982] that the Federal Open Market Committee would tolerate "growth somewhat above the targeted ranges ... for a time in circumstances in which it appeared that precautionary or liquidity motivations, during a period of economic uncertainty and turbulence, were leading to stronger than anticipated demands for money." (p. 747)

Deregulation and financial innovation can affect monetary growth rates, so interpretation of the latter must account for the former. In particular, from the early 1980s onward in both the United Kingdom and the United States, the large increases in real money might have simply reflected portfolio adjustments due to changed interest rate differentials. Or, they might have induced higher inflation in the future. These two alternatives suggest very different responses on the part of the central bank. Considerable evidence supports the interpretation of a portfolio shift, including the model (20) itself, the models for M1 in Hendry and Ericsson (1991b) and Baba, Hendry, and Starr (1992), the historical track record of the Bank of England and the Federal Reserve Board, and the actual low inflation rates in both countries during the late 1980 s and the 1990 s.

Third, super exogeneity rules out the role of model-based expectations in (20), in which case the Lucas critique is not empirically germane. Data-based predictors 
are allowable, so equilibrium correction models such as (20) can have a forwardlooking interpretation; see Hendry and Ericsson (1991b). Specifically, current and lagged inflation enter $(20)$ as approximately $-0.3\left(\Delta p_{t}+\Delta^{2} p_{t}\right)$, where $\Delta p_{t}+\Delta^{2} p_{t}$ is a natural predictor of next period's inflation. Flemming (1976, Chapter 7) proposes similar functions for forming expectations about inflation.

Even when super exogeneity holds, policy can and (in general) does affect agent behavior. It does so through the variables entering the conditional model, albeit not through the parameters of that model. Government policy might well affect inflation and interest rates, and so the demand for money. However, under super exogeneity, the precise mechanism that the government adopts for such a policy does not affect agent behavior, except insofar as the mechanism affects actual outcomes.

\section{Conclusions}

This paper develops a framework for economic extensions of empirical models, and it applies that framework to the dynamic model of broad money demand in Hendry and Ericsson (1991a). The analysis clarifies the importance of coherently measured time series when building and evaluating empirical models. It also reflects the progressive nature of empirical research. Econometric equations are not one-off laws cast in stone, but are flexible tools for understanding the economy and for helping guide both policy and forecasting; see Pagan (1987).

Empirically, the broadening of measured money and the concurrent financial innovations required a measure of the opportunity cost that reflects those changes. Consequently, a measure was developed that depends on the proportion of non-interestbearing money. With that measure, the cointegrating vector remains constant over the extended sample, which is nearly $20 \%$ longer than the initially available dataset. The coefficients in the dynamic model itself are also virtually unchanged for the extended sample, once the new measure of opportunity cost is incorporated and the dummy for deregulation is extended to account for the 1986 Building Societies Act. Even so, the dynamic equation's error variance does increase over the extended sample. That increase may reflect effects from interest rate volatility similar to the effects on U.S. M1 from the risk of capital loss induced by volatile long-term interest rates; see Baba, Hendry, and Starr (1992).

The model's degree of empirical constancy seems reasonable, especially in light of the very large changes over the last 120 years in the variables' magnitudes, in the underlying economic structure, and in the financial system. Nevertheless, several developments could improve the model's fit in the most recent period and thereby improve its constancy. First, a more consistent series for money might be constructed, allowing for the liabilities of building societies throughout. Second, the measure of opportunity cost also could be improved. Specifically, the effects of interest-rate 
volatility and learning adjustment could be modeled with higher frequency data and then mapped to annual values; and series on the own rate could be gathered. Third, the indicator (dummy) variables require more study. They are endogenously chosen to remove nonconstancies and may reflect non-modeled factors, such as data measurement errors, structural changes, and omitted transitions. Equally, war, financial innovation, and deregulation have complex effects on the economy, typically generating the most perturbed and informative data of the sample. Finally, econometrics has progressed during the model's forecast period. Methods for estimating nonlinear equilibrium correction models are now available, as are techniques for estimating transition effects; see Escribano (1996) and Granger and Teräsvirta (1993) respectively. Also, the technology of multivariate cointegration analysis is bound to yield additional insights if the marginal models can be developed as congruent relations. 


\section{References}

Anderson, G. J., and D. F. Hendry (1984) "An Econometric Model of United Kingdom Building Societies", Oxford Bulletin of Economics and Statistics, 46, 3, 185-210.

Attfield, C. L. F., D. Demery, and N. W. Duck (1995) "Estimating the UK Demand for Money Function: A Test of Two Approaches", mimeo, Department of Economics, University of Bristol, Bristol, England, November.

Baba, Y., D. F. Hendry, and R. M. Starr (1992) "The Demand for M1 in the U.S.A., 1960-1988", Review of Economic Studies, 59, 1, 25-61.

Banerjee, A., D. F. Hendry, and G. E. Mizon (1996) "The Econometric Analysis of Economic Policy", Oxford Bulletin of Economics and Statistics, 58, 4, 573-600.

Barnett, W. A. (1980) "Economic Monetary Aggregates: An Application of Index Number and Aggregation Theory", Journal of Econometrics, 14, 1, 11-48.

Cagan, P. (1956) "The Monetary Dynamics of Hyperinflation", Chapter 2 in M. Friedman (ed.) Studies in the Quantity Theory of Money, University of Chicago Press, Chicago, 25-117.

Chow, G. C. (1960) "Tests of Equality Between Sets of Coefficients in Two Linear Regressions", Econometrica, 28, 3, 591-605.

Clements, M. P., and D. F. Hendry (1996) "Intercept Corrections and Structural Change", Journal of Applied Econometrics, 11, 5, 475-494.

la Cour, L. F. (1996) “The Problem of Measuring 'Money': Results from an Analysis of Divisia Monetary Aggregates for Denmark", mimeo, Institute of Statistics, University of Copenhagen, Copenhagen, Denmark, March.

Dickey, D. A., and W. A. Fuller (1981) "Likelihood Ratio Statistics for Autoregressive Time Series with a Unit Root", Econometrica, 49, 4, 1057-1072.

Diewert, W. E. (1976) "Exact and Superlative Index Numbers", Journal of Econometrics, 4, 2, 115-145.

Doornik, J. A., and H. Hansen (1994) "An Omnibus Test for Univariate and Multivariate Normality", Discussion Paper No. W4\&91, Nuffield College, Oxford, England, November.

Doornik, J. A., and D. F. Hendry (1992) PcGive Version 7: An Interactive Econometric Modelling System, Institute of Economics and Statistics, University of Oxford, Oxford, England.

Doornik, J. A., and D. F. Hendry (1994) PcGive 8.0: An Interactive Econometric Modelling System, International Thomson Publishing, London.

Doornik, J. A., and D. F. Hendry (1996) GiveWin: An Interface to Empirical Modelling, International Thomson Business Press, London (Version 1.0). 
Engle, R. F. (1982) “Autoregressive Conditional Heteroscedasticity with Estimates of the Variance of United Kingdom Inflation", Econometrica, 50, 4, 987-1007.

Engle, R. F., and C. W. J. Granger (1987) "Co-integration and Error Correction: Representation, Estimation, and Testing", Econometrica, 55, 2, 251-276.

Engle, R. F., and D. F. Hendry (1993) "Testing Super Exogeneity and Invariance in Regression Models", Journal of Econometrics, 56, 1/2, 119-139.

Ericsson, N. R., D. F. Hendry, and K. M. Prestwich (1997) "Friedman and Schwartz (1982) Revisited: Assessing Annual and Phase-average Models of Money Demand for the United Kingdom", mimeo, Board of Governors of the Federal Reserve System, Washington, D.C., November.

Ericsson, N. R., and J. S. Irons (1995a) "Book Review of Applied Econometric Techniques by Keith Cuthbertson, Stephen G. Hall, and Mark P. Taylor", Econometric Reviews, 14, 1, 121-133.

Ericsson, N. R., and J. S. Irons (1995b) "The Lucas Critique in Practice: Theory Without Measurement", Chapter 8 in K. D. Hoover (ed.) Macroeconometrics: Developments, Tensions and Prospects, Kluwer Academic Publishers, Boston, Massachusetts, 263-312 (with discussion).

Ericsson, N. R., and S. Sharma (1996) "Broad Money Demand and Financial Liberalization in Greece", International Finance Discussion Paper No. 559, Board of Governors of the Federal Reserve System, Washington, D.C., July.

Escribano, A. (1985) "Non-linear Error-correction: The Case of Money Demand in the U.K. (1878-1970)", mimeo, University of California at San Diego, La Jolla, California, December.

Escribano, A. (1996) "Nonlinear Error Correction: The Case of Money Demand in the U.K. (1878-1970)", mimeo, Department of Statistics and Econometrics, Universidad Carlos III de Madrid, Madrid, Spain, July.

Flemming, J. S. (1976) Inflation, Oxford University Press, Oxford.

Friedman, M., and A. J. Schwartz (1982) Monetary Trends in the United States and the United Kingdom: Their Relation to Income, Prices, and Interest Rates, 18671975, University of Chicago Press, Chicago.

Godfrey, L. G. (1978) "Testing Against General Autoregressive and Moving Average Error Models When the Regressors Include Lagged Dependent Variables", Econometrica, 46, 6, 1293-1301.

Goldfeld, S. M., and D. E. Sichel (1990) "The Demand for Money", Chapter 8 in B. M. Friedman and F. H. Hahn (eds.) Handbook of Monetary Economics, Volume 1, North-Holland, Amsterdam, 299-356.

Granger, C. W. J., and T. Teräsvirta (1993) Modelling Nonlinear Economic Relationships, Oxford University Press, Oxford. 
Green, C. J. (1987) "Money Market Arbitrage and Commercial Banks' Base Rate Adjustments in the United Kingdom", Bulletin of Economic Research, 39, 4, 273296.

Hacche, G. (1974) "The Demand for Money in the United Kingdom: Experience Since 1971", Bank of England Quarterly Bulletin, 14, 3, 284-305.

Hansen, B. E. (1992) "Testing for Parameter Instability in Linear Models", Journal of Policy Modeling, 14, 4, 517-533.

Harvey, A. C. (1981) Time Series Models, Philip Allan, Oxford.

Harvey, A. C., and N. Shephard (1993) "Structural Time Series Models", Chapter 10 in G. S. Maddala, C. R. Rao, and H. D. Vinod (eds.) Handbook of Statistics, Volume 11, North-Holland, Amsterdam, 261-302.

Hawtrey, R. G. (1938) A Century of Bank Rate, Longmans, Green and Company, London.

Hendry, D. F. (1994) "HUS Revisited", Oxford Review of Economic Policy, 10, 2, 86-106.

Hendry, D. F. (1995) Dynamic Econometrics, Oxford University Press, Oxford.

Hendry, D. F. (1996) "On The Constancy of Time-series Econometric Equations", Economic and Social Review, 27, 5, 401-422.

Hendry, D. F., and J. A. Doornik (1996) Empirical Econometric Modelling Using PcGive 9.0 for Windows, International Thomson Business Press, London.

Hendry, D. F., and N. R. Ericsson (1991a) "An Econometric Analysis of U.K. Money Demand in Monetary Trends in the United States and the United Kingdom by Milton Friedman and Anna J. Schwartz", American Economic Review, 81, 1, 8-38.

Hendry, D. F., and N. R. Ericsson (1991b) "Modeling the Demand for Narrow Money in the United Kingdom and the United States", European Economic Review, 35, 4, 833-881 (with discussion).

Hendry, D. F., and G. E. Mizon (1978) "Serial Correlation as a Convenient Simplification, Not a Nuisance: A Comment on a Study of the Demand for Money by the Bank of England", Economic Journal, 88, 351, 549-563.

Hendry, D. F., and G. E. Mizon (1996) "Selecting Econometric Models for Policy Analysis by Forecast Accuracy", mimeo, Nuffield College, Oxford, England.

Hendry, D. F., and M. S. Morgan (eds.) (1995) The Foundations of Econometric Analysis, Cambridge University Press, Cambridge.

Jevons, W. S. (1884) Investigations in Currency and Finance, Macmillan, London. 
Johansen, S. (1992) "Testing Weak Exogeneity and the Order of Cointegration in UK Money Demand Data", Journal of Policy Modeling, 14, 3, 313-334.

Johansen, S. (1995) Likelihood-based Inference in Cointegrated Vector Autoregressive Models, Oxford University Press, Oxford.

Judd, J. P., and J. L. Scadding (1982) "The Search for a Stable Money Demand Function: A Survey of the Post-1973 Literature", Journal of Economic Literature, 20, 3, 993-1023.

Keynes, J. M. (1930) A Treatise on Money, Macmillan, London (Volumes 1 and 2).

Keynes, J. M. (1940) How to Pay for the War: A Radical Plan for the Chancellor of the Exchequer, Harcourt, Brace and Company, New York.

Lubrano, M., R. G. Pierse, and J.-F. Richard (1986) "Stability of a U.K. Money Demand Equation: A Bayesian Approach to Testing Exogeneity", Review of Economic Studies, 53, 4, 603-634.

Lucas, Jr., R. E. (1976) "Econometric Policy Evaluation: A Critique", in K. Brunner and A. H. Meltzer (eds.) Carnegie-Rochester Conference Series on Public Policy: The Phillips Curve and Labor Markets, Volume 1, Journal of Monetary Economics, Supplement, 19-46 (with discussion).

MacKinnon, J. G. (1991) "Critical Values for Cointegration Tests", Chapter 13 in R. F. Engle and C. W. J. Granger (eds.) Long-run Economic Relationships: Readings in Cointegration, Oxford University Press, Oxford, 267-276.

MacKinnon, J. G., and H. White (1985) "Some Heteroskedasticity-consistent Covariance Matrix Estimators with Improved Finite Sample Properties", Journal of Econometrics, 29, 3, 305-325.

Marshall, A. (1926) Official Papers, Macmillan, London.

Messer, K., and H. White (1984) "A Note on Computing the Heteroskedasticity Consistent Covariance Matrix Using Instrumental Variable Techniques", Oxford Bulletin of Economics and Statistics, 46, 2, 181-184.

Muellbauer, J. N. J. (1994) "The Assessment: Consumer Expenditure", Oxford Review of Economic Policy, 10, 2, 1-41.

Muellbauer, J. N. J. (1997) "Measuring Financial Liberalization in the UK Mortgage Market", mimeo, Nuffield College, Oxford, England, March.

Nicholls, D. F., and A. R. Pagan (1983) "Heteroscedasticity in Models with Lagged Dependent Variables", Econometrica, 51, 4, 1233-1242.

Pagan, A. R. (1987) "Three Econometric Methodologies: A Critical Appraisal", Journal of Economic Surveys, 1, 1, 3-24. 
Patterson, K. D. (1993) "The Impact of Credit Constraints, Interest Rates and Housing Equity Withdrawal on the Intertemporal Pattern of Consumption - A Diagrammatic Analysis", Scottish Journal of Political Economy, 40, 4, 391-407.

Ramsey, J. B. (1969) "Tests for Specification Errors in Classical Linear Least-squares Regression Analysis", Journal of the Royal Statistical Society, Series B, 31, 2, $350-371$.

Salkever, D. S. (1976) "The Use of Dummy Variables to Compute Predictions, Prediction Errors, and Confidence Intervals", Journal of Econometrics, 4, 4, 393-397.

Sprenkle, C. M., and M. H. Miller (1980) "The Precautionary Demand for Narrow and Broad Money", Economica, 47, 188, 407-421.

Teräsvirta, T., and H. M. Anderson (1992) "Characterizing Nonlinearities in Business Cycles Using Smooth Transition Autoregressive Models", Journal of Applied Econometrics, 7, Supplement, S119-S136.

Topping, S. L., and S. L. Bishop (1989) "Breaks in Monetary Series", Discussion Paper No. 23, Technical Series, Bank of England, London, England, February.

Volcker, P. A. (1982) "Statements to Congress", Federal Reserve Bulletin, 68, 12, 747-753.

White, H. (1980) "A Heteroskedasticity-consistent Covariance Matrix Estimator and a Direct Test for Heteroskedasticity", Econometrica, 48, 4, 817-838. 